\title{
Thermal Radiation from Vapour Cloud Explosions
}

\author{
M.A. Hadjipanayis ${ }^{\mathrm{a}}$, F. Beyrau ${ }^{\mathrm{a}}$, R.P. Lindstedtat ${ }^{\mathrm{a}, *}$, G. Atkinson ${ }^{\mathrm{b}}$, L. Cusco ${ }^{\mathrm{b}}$ \\ ${ }^{a}$ Department of Mechanical Engineering, Imperial College, Exhibition Road, London \\ SW7 2AZ, United Kingdom \\ ${ }^{b}$ Health \& Safety Laboratory, Harpur Hill, Buxton SK17 9JN, United Kingdom
}

\begin{abstract}
The current study estimates the radiation flux emitted from hot extended gas clouds characteristic of vapour cloud explosions along with the corresponding level of irradiance posed on particles suspended in the unburnt part of the cloud ahead of an advancing flame front. The data presented permits an assessment of the plausibility of combustion initiation by such particles due to forward thermal radiation. The thermal radiation will depend on the emissivity of the burned volume, which relates to the concentration of gaseous and particulate combustion products. A sensitivity analysis has been carried out to account for variations in the equivalence ratio, mixture pressure and radiative heat losses. The spatial distribution of irradiance ahead of the flame front has been computed by introducing appropriate geometrical factors to explore the impact of cloud size. Using fuel rich ethylene-air mixtures it has been shown that high flame emissivities can be achieved at path lengths of order $1 \mathrm{~m}$ even in the presence of very low soot volume fractions. The emissivity of gas-soot mixtures will hence be mainly determined by the soot concentration and to a lesser extent by the mixture temperature. Our analysis suggests that the role of forward thermal radiation as a contributing factor to flame propagation in large scale vapour cloud explosions can not currently be ruled out.
\end{abstract}

Keywords: Radiation Induced Ignition, Vapour Cloud Explosions, Soot

\footnotetext{
*Corresponding author. Fax: +44 2075893905

Email address: p.lindstedt@imperial.ac.uk (R.P. Lindstedt)
}

Preprint submitted to Process Safety and Environmental Protection October 9, 2014 


\section{Introduction}

Radiation often dominates heat transfer process at high temperatures (Hottel, 1958). Consequently, thermal radiation makes a decisive contribution to the overall energy transport in many combustion systems (Nathan et al., 2012). However, the influence of radiative heat transfer in unconfined vapour cloud explosions (UVCE) and on the corresponding rate of flame propagation is not yet fully understood. Particles heated by high levels of radiation can induce ignition of an adjacent explosive charge. Moore and Weinberg $(1981,1983,1987)$ have shown that this may become important in vapour cloud explosions (VCE). The emission of strong radiative heat loads, emanating from the hot product cloud, on particles situated in the reactants can be sufficient to ignite the surrounding fuel-air mixture. In order to have a notable effect, ignition centres have to be formed well ahead of the advancing flame, thus relatively long length scales and short time scales are essential. Beyrau et al. (2013) explored the potential of fine particles acting as initiators of combustion in flammable mixtures upon irradiation using a near infrared (NIR) laser source. The experimental investigation featured powders with widely different characteristics (type, size, morphology, etc.) and times to ignition were established. In particular, ignition time scales $\simeq 100 \mathrm{~ms}$ were obtained in a stoichiometric butane-air mixture at an irradiance $<600$ $\mathrm{kW} / \mathrm{m}^{2}$ using substrates coated with a commercially available carbon black powder (acetylene black). In a recent study, Beyrau et al. (2014) quantified the heating process of such irradiated powders using time-resolved emission spectroscopy. The particle surface temperatures necessary to cause ignition of a surrounding charge were also obtained revealing two different ignition 
regimes based on the reactivity of the powder.

Fine particles may be raised by an expanding gas cloud and become suspended in the unburnt gas mixture. The dispersion of dusts/particulates ahead of a propagating flame front is a well established phenomenon. According to Klemens et al. (2006), fine dusts can be raised by expansion waves induced from a moderate local explosion. For example, in coal mines the pressure wave of a weak methane explosion can disperse dust deposits leading to the formation of an explosive dust-air cloud. The dust can be ignited by the hot methane-air products causing a (strong) secondary explosion. The phenomenon has been the subject of studies exploring the interaction of deposited dust layers with shockwaves (e.g. Fedorov (2004); Gerrard (1963)). In addition, the dispersion of coal dust deposits by an advancing methane-air flame has been studied experimentally by Lu et al. (2002) in a laboratory scale flame tube. Hydrogen-air explosions can exhibit visible luminosity due to suspended inert particles while, in hydrogen jet flames, naturally occurring particulates present in the air entrained into the reaction region can also be a source of visible light emission (Shirvill et al., 2012). Finally, inert dust can suppress dust explosions and hence can be employed for the prevention and mitigation of dust explosions in coal mines (Amyotte, 2006).

The levels of flame surface flux reported in literature from various combustion systems can be seen in Table 1 . There is a notable absence of data on the premixed systems considered in the current study. However, Holbrow et al. (2000) examined the radiative power densities from fireballs produced from vented dust explosions. Average surface emissive power (ASEP) of up to $275 \mathrm{~kW} / \mathrm{m}^{2}$ have been measured with coal dust and up to $2900 \mathrm{~kW} / \mathrm{m}^{2}$ 
with aluminium. In heterogeneous combustion systems, reaction takes place at the surface of the condensed fuel, hence, dust explosions emit continuous Planck's radiation which is a function of the particle temperature. This can explain the discrepancy between results obtained with aluminium and coal dust. Thermal radiation from fireballs produced in Boiling Liquid Expanding Vapour Explosion (BLEVE) have also been examined. These turbulent flames emit non-luminous infrared radiation emanating from the emission bands of gaseous combustion products and luminous continuous radiation by soot particles in the visible and infrared (Tien and Lee, 1982; Viskanta and Mengüç, 1987). High emissivities can be achieved due to the high soot concentration and large burnt gas volume. Measurements by Roberts et al. (2000) indicate $\mathrm{SEP}_{\max }$ up to $550 \mathrm{~kW} / \mathrm{m}^{2}$ while extrapolated results from Roberts (1981) suggest that $\mathrm{SEP}_{\max }$ up to $450 \mathrm{~kW} / \mathrm{m}^{2}$ can be achieved. Average SEPs from optically thick diffusion flames can typically be expected to be of the order $200-300 \mathrm{~kW} / \mathrm{m}^{2}$ with maximum spot values of $350-450 \mathrm{~kW} / \mathrm{m}^{2}$ as shown in Table 1. Similarly, radiation emanating from gaseous products and soot is a well known design consideration in gas turbine burners. Theoretical results, obtained from spray-stabilised flames in pressurised enclosures, suggest that flame surface flux around $1500 \mathrm{~kW} / \mathrm{m}^{2}$ can be achieved (Lefebvre, 1984; Mengüç et al., 1986; Najjar, 1985).

Experiments by Hardee et al. (1978) involving fireballs, produced by nonpremixed as well as premixed stoichiometric methane-air mixtures (1.5 and 10 $\mathrm{kg}$ of $\mathrm{CH}_{4}$ ), showed that premixed clouds, although appearing less luminous and relatively more transparent than the corresponding non-premixed case, emit higher flame surface fluxes due to the increased temperature of the gas. 


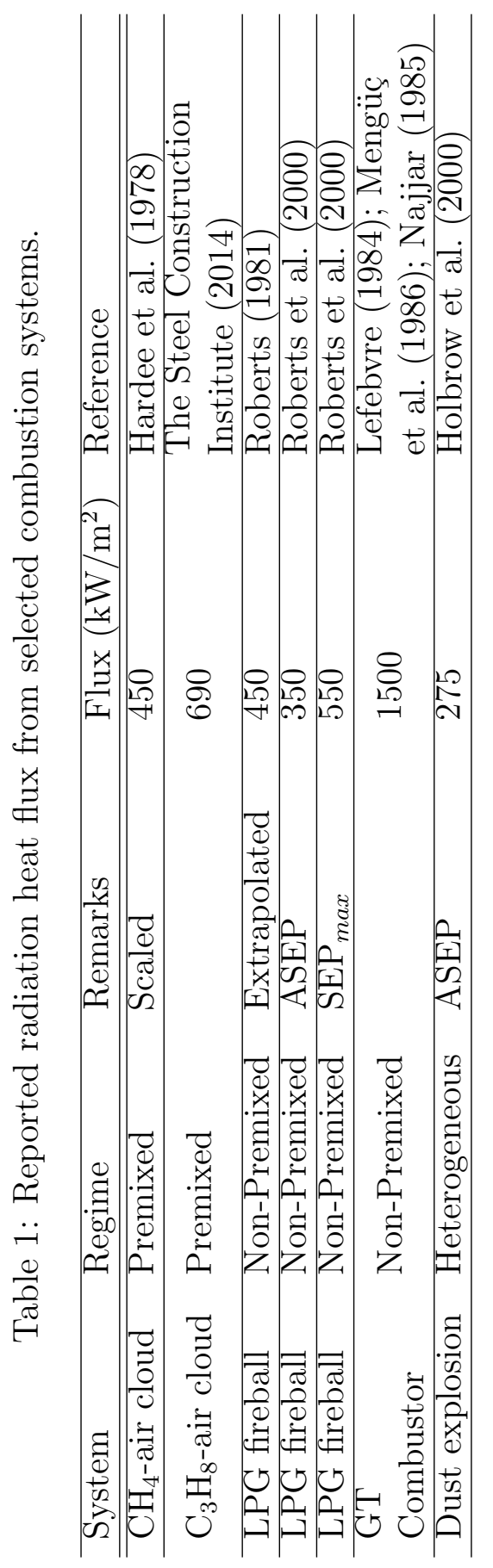


Scaled results suggest that maximum flame surface fluxes up to $450 \mathrm{~kW} / \mathrm{m}^{2}$ could be expected from a premixed cloud. The argument is corroborated by considering results from Dorofeev et al. (1996) who collected light from stoichiometric and fuel rich propane-air detonations. Measurements showed that significantly more light is emitted during the premixed burning phase than at any subsequent excess fuel burnout. In a detonation wave, both the temperature and pressure are much higher than in conventional deflagration, which will ultimately induce increased gas emissivities. Radiation measurement obtained from premixed propane-air clouds suggest spot values of approximately $700 \mathrm{~kW} / \mathrm{m}^{2}$ (The Steel Construction Institute, 2014). In these particular tests, carbon based dusts were laid on the floor of the explosion chamber to examine if they would cause secondary ignition due to forward thermal radiation. While no acceleration that could be attributed to radiative heating was observed, previous work has shown (Beyrau et al., 2013) that ignition timescales can vary by orders of magnitude for different carbon black powders. Explosions often deviate from stable deflagrations or detonations occurring under ideal conditions and in unimpeded geometries (Oran and Williams, 2012). Accordingly, in a real incident local gas pockets may achieve high pressure and temperature without subsequently developing into a detonation. Hence, radiative properties obtained from local events may still be important for an unsuccessful deflagration-to-detonation transition (DDT).

There is an obvious lack of radiation measurements in large scale premixed systems related to explosions and the actual level of thermal radiation emitted from a VCE remains conjectural. Radiation emanates from both 
gaseous and particulate combustion products, which are at higher temperatures for premixed flames and hence higher radiation levels are expected. Moore and Weinberg (1981) reported theoretical values of blackbody radiation up to $1 \mathrm{MW} / \mathrm{m}^{2}$ assuming a burnt gas temperature $\left(T_{b}\right)$ at $2050 \mathrm{~K}$ as representative of a stoichiometric mixture and unit emissivity. Although laboratory premixed flames vary from the blackbody condition, in vapour cloud explosions, the shear size of combustion product cloud is believed to yield higher emissivities (Finkelnburg, 1949). Additionally, soot can be generated as a result of local inhomogeneities in the equivalence ratio or in fuel rich regions. The presence of a large number of very small unburned carbon particles, initially expected to be in thermal equilibrium with the surrounding combustion products, will induce higher flame emissivities. The true level of radiant heat emitted will hence be affected by the local mixture stoichiometry and vapour clouds resulting from accidental leaks are likely to be stratified. Atkinson and Cusco (2011) have further proposed that the theory of radiatively ignited particulates may explain the unusual flame propagation rate observed in the 2005 Buncefield explosion. The objective of the current study is, hence, to estimate the flame surface flux expected from large premixed systems and examine the corresponding level of irradiance posed on particles suspended in the unburned gas mixture. A comparison of such theoretical estimates with the experimentally measured ignition time data (Beyrau et al., 2013) is vital for evaluation purposes.

The current study extends previous efforts by consideration of parameters relevant to the mechanism proposed by Atkinson and Cusco (2011). Flame radiation emitted from the principal gaseous products $\mathrm{H}_{2} \mathrm{O}$ and $\mathrm{CO}_{2}$ at large 
path lengths is obtained along with the corresponding emissivity. Moreover, a sensitivity analysis is carried out based on laminar flame calculations for fuel-air mixtures using detailed chemistry to account for variations in the equivalence ratio, pressure and heat losses. The resulting spatial distribution of irradiance on particles present in the unburned gas mixture is calculated using appropriate view factors. Finally, the influence of the flame temperature, size and location relative to the irradiated particle is considered.

\section{Material and Methods}

\subsection{Estimation of Flame Radiation}

Flame radiation originates from gaseous combustion products like water vapour $\left(\mathrm{H}_{2} \mathrm{O}\right)$, carbon dioxide $\left(\mathrm{CO}_{2}\right)$, carbon monoxide $(\mathrm{CO})$ and particles such as soot. Emissions from carbon monoxide and pollutants such as sulphur dioxide and nitrous oxide, are minimal compared to the water vapour and carbon dioxide and can therefore be neglected. The product gas quantities and temperatures are intrinsic flame properties which depend on the type of fuel, initial temperature and pressure, and equivalence ratio. The absorption/emission spectrum of each species is banded even at the high temperatures encountered in flames. Consequently, spectral considerations have to be taken into account without, however, the need for detailed line-byline calculations. Typically, computations can be performed by dividing the spectrum of interest in smaller (narrow or wide) bands and assume that the discrete absorption lines of each gas can be represented by a smooth profile. Theoretical narrow band models provide the mean spectral emissivity over these smaller spectral ranges by utilising statistical methods to characterise 
the exact emission lines. Wide-band models provide the total absorption over individual bands for each radiating gas using empirical relations fitted to data obtained from experimental measurements. Detailed discussion on narrow and wide band models can be found in Tien and Lee (1982); Viskanta and Mengüç (1987). In this study, the emissivity of combustion products has been computed using the spectrally resolved absorption coefficient data at flame temperatures obtained by Ludwig et al. (1973).

For luminous flames, radiation originates from soot particles and gaseous combustion products. Soot particles emit continuous radiation over the visible and infrared spectrum. The structure of soot consists of fused carbon particles ranging from a few nanometers to a few hundred nanometers in diameter. The interaction of soot with incident radiation follows the Mie theory (Van de Hulst, 1957) and scattering is negligible compared to absorption since the radiation wavelengths are larger than the soot particle diameter $(\pi D / \lambda<1)$. It has been shown by Yuen and Tien (1977) that in luminous flames the exact closed-form expressions for soot emissivity $\left(\varepsilon_{s}\right)$, can be approximated based by,

$$
\varepsilon_{s}=1-\exp \left(-k_{s} L\right)
$$

where $L$ is the path length of the flame and $k_{s}$ is a soot-emission parameter given by,

$$
k_{s}=3.6 \frac{c T_{b}}{c_{2}}
$$

where $c_{2}=1.44 \times 10^{-2} \mathrm{mK}$ is the Planck's second constant and $T_{b}$ is the 
flame temperature. The constant $c$ is given by,

$$
c=36 \pi f_{v} \frac{n^{2} k}{\left[n^{2}-(n k)^{2}+2\right]^{2}+4 n^{2} k^{2}}
$$

where $n$ and $k$ are the infrared-average optical constants of soot and $f_{v}$ is the soot volume fraction.

The above non-grey analysis has been adopted in a number of studies (Mason et al., 2009; Wiedenhoefer and Reitz, 2003; Yoshikawa and Reitz, 2009). Howell et al. (2011) suggested that $c /\left(c_{2} f_{v}\right)=350 \mathrm{~m}^{-1} \mathrm{~K}^{-1}$ irrespective of the type of soot. However, current evidence suggests that the constant $c$, should be computed on the basis of refractive index $\widetilde{m}=n-i k$. If, for example, $\widetilde{m}=1.8-1.0 i$ (Shaddix and Williams, 2007) is used higher absorptivities are obtained. Dalzell and Sarofim (1969) proposed a set of experimental values for the refractive index of soot $(\widetilde{m}=n-i k)$ determined from reflectance measurements and a dispersion model for fitting to the data. Lee and Tien (1981) used a revised model in conjunction with transmission measurements and reported different values for the optical constants of soot. Furthermore, Habib and Vervisch (1988) suggested that the variation of the refractive index of soot with respect to the hydrogen content of the fuel can be calculated via two bound-one free dispersion equations. In the current study, the refractive index $\widetilde{m}=1.56-0.56 i$ is used which has been frequently citied by the combustion community (Smyth and Shaddix, 1996).

Assuming that soot behaves like a grey body, the emissivity of a luminous flame $\left(\varepsilon_{f}\right)$ emanating from soot and combustion products can be expressed 
by Eq. (4).

$$
\varepsilon_{f}=\varepsilon_{g}+\varepsilon_{s}-\varepsilon_{g} \varepsilon_{s}
$$

The emissivity of the gaseous combustion products $\left(\varepsilon_{g}\right)$ can be obtained using non-luminous flame analysis alone. Therefore, the problem of calculating the emissivity from luminous flames can be greatly simplified by using Eq. (4). Moreover, it can be deduced that radiation from a luminous flame is equal to the emissivity of gas and soot alone minus a correction factor. Mixtures of gas and soot have been considered in this article to quantitively highlight the importance of the presence of soot particles in vapour cloud explosions.

Ideally, a hybrid model should be used to account for potential irregularities in luminosity expected in the event of cloud stratification. Similarly, in pool fires the flame is split into to a lower clear luminous burning zone and an upper sooty black smoke zone (Hailwood et al., 2009; Rew et al., 1997). The inhomogeneities in the concentration of combustion products (gas and soot) and fluctuations in temperature caused by turbulence will have an effect on the resulting thermal radiation. However, detailed accounting for variations induced by turbulence, fuel stratification and spatial luminosity variations are likely to be strongly scenario dependent and correspondingly complex. The difficulties associated with considering such effects outweigh the current objective of providing estimated radiation fluxes. Hence, a homogenous temperature and concentration model was implemented. 


\subsection{Geometric View Factor}

The level of irradiance received by particles located ahead of an advancing flame will depend on (i) the flame surface flux, (ii) the geometric view factor between the flame and particles and (iii) the absorption of radiation by the unburned fuel-air mixture. To estimate the irradiance received by such a particle, the flame front is represented by an appropriate physical model which entails knowledge of the flame heat release rate and shape. Moore and Weinberg (1983) represented the flame with a planar circular shape propagating along its central axis. This is considered a solid flame model since the flame is approximated as a solid body of equivalent shape (Davis and Bagster, 1989).

The total heat transfer by radiation $\left(Q_{1-2}\right)$ from the flame (Body 1 ) with emissive power $E_{f}$ to the target (Body 2) is given by Eq. (5)

$$
Q_{1-2}=E_{f} F_{1-2} A_{1}
$$

where, $F_{1-2}$ is the geometric view factor between the flame and the target and $A_{1}$ is emitting area.

The irradiance received by a target $\left(q_{2}\right)$ of area $A_{2}$ is calculated via Eq. (6).

$$
q_{2}=Q_{1-2} / A_{2}
$$

The flame is assumed to emit radiation like a solid body thus the corresponding emissive power $\left(E_{f}\right)$ can be expressed by,

$$
E_{f}=\varepsilon_{f} \sigma T_{b}^{4}
$$


where $\varepsilon_{f}$ is the flame emissivity and $\sigma=5.6704 \times 10^{-8} \mathrm{~W} / \mathrm{m}^{2} \mathrm{~K}^{4}$ is the Stefan-Boltzmann constant.

Equations (5 - 7) allow the calculation of irradiance received by a particle located in the unburned region assuming the flame emits radiation like a solid body and there is no attenuation from the interleaving unburned fuelair mixture. In fact, the level of absorption is essentially determined by the spectral overlap of the emitted radiation and absorption bands of the unburned gas mixture. In order to examine to what extent the assumption of no attenuation is correct, the case of collimated blackbody radiation into an ethylene-air mixture of unit stoichiometry at 1 atm, $298 \mathrm{~K}$ and 100\% humidity was considered. In this case, there are no geometrical effects and, hence, the attenuation of radiation with distance $(x)$ can be described by Beer's law (Eq. 8), assuming a mean absorption coefficient $(k)$. Ethylene was specifically chosen due to its strong near and mid infrared absorption bands (Moore and Weinberg, 1983).

$$
I=I_{o} \exp ^{-k x}
$$

Lastly, an appropriate geometrical factor between the flame and particles $F_{1-2}$ is required. This depends on the geometrical characteristics of the emitter and target. For the purpose of this study, three well known view factors, that of straight cylinder (Mudan, 1987), and two parallel coaxial disks and coaxial squares have been selected (Howell et al., 2011). In summary, in the calculation of the irradiance received by particles present in the reactant gas, the flame is (i) modelled as a circular or rectangular planar shape propagating along its centre axis or as a squat cylinder propagating radially, 
(ii) flame surface fluxes are obtained from Planck's radiation law and (iii) attenuation from the fuel-air mixture is neglected unless stated. Hence, a symmetric cloud shape with a vertical axis of symmetry is assumed and upwards radiative fluxes were not considered due to the reduced likelihood of particulate material being suspended above the cloud.

\subsection{Estimation of Flame Properties}

Flame properties required for this study have been computed using an inhouse code developed by Jones and Lindstedt (1988). The chemistry is based on the work of Lindstedt and coworkers (Lindstedt and Meyer, 2002; Lindstedt et al., 2011), the mechanism consists of 168 reactions and 33 species. A laminar flame, propagating freely through a premixed mixture was considered based on the constant pressure assumption. The boundary conditions of pressure $\left(P_{0}\right)$ and temperature $\left(T_{0}\right)$ were set to $101325 \mathrm{~Pa}$ and $298 \mathrm{~K}$ respectively. Adiabatic combustion was assumed in all cases except when the effect of radiative heat losses was examined. The burnt gas temperature and species concentration, necessary for the calculation of the flame emissivity, were extracted from the simulations. The computational domain for methane-air cases was resolved using 318 nodes featuring a mesh size of $\sim 3 \mu \mathrm{m}$ in the reaction zone, while for ethylene and ethane-air 214 nodes were used corresponding to a mesh size of $\sim 4 \mu \mathrm{m}$ in the reaction zone.

Illustrative species profiles are shown in Fig. 1, these include $\mathrm{CH}_{4}, \mathrm{O}_{2}$ and $\mathrm{CO}$ and final product species $\mathrm{H}_{2} \mathrm{O}$ and $\mathrm{CO}_{2}$. Carbon monoxide is formed during the combustion process followed by further oxidation to $\mathrm{CO}_{2}$. Therefore, the $\mathrm{CO}$ profile features a maximum within the reaction zone. Principal combustion products, water and carbon monoxide, increase steadily throughout 
the domain. The middle plot shown in Fig. 1 shows the rate of production (+ve) and consumption (-ve) of fuel, oxygen and carbon monoxide. The temperature profile rises steadily during the carbon monoxide to carbon dioxide oxidisation phase as seen in the bottom plot.

Heat losses have been included in the computation by correcting the flame temperature $\left(T_{b}\right)$ via Eq. (9), where $T_{a d}$ is the adiabatic flame temperature and $\beta$ is the heat loss factor. The heat loss factor $(\beta)$ approach has been used in a number of studies over a considerable period of time, e.g. Jones and Lindstedt (1988), to include the $\mathrm{T}^{4}$ law impact on laminar flame structures as part of radiation calculations. For example, the approach was used by Fairweather et al. (1992) as part of a calculation procedure for the estimation of radiative transfer from turbulent reacting jets.

$$
T_{b}=T\left[1-\beta\left(\frac{T}{T_{a d}}\right)^{4}\right]
$$

The objective of the laminar flame calculation is to determine the temperature and concentrations of principal combustion products. The computationally determined major species concentrations $\left(\mathrm{x}_{\mathrm{i}}\right)$ and temperatures can seen in Table 2 along with the corresponding boundary conditions used for each case. The thermal expansion ratio $(\tau)$ calculated via Eq. (10), where $\rho$ is the density and the subscripts ' 0 ' and 'b' indicate the values in the reactants and burnt products, is also listed for each case.

$$
\tau=\rho_{0} / \rho_{b}-1
$$

The calculated flame temperatures obtained for all methane-air cases are 
shown in Fig. 2. The top and middle rows illustrate the influence of the mixture stoichiometry and heat losses via radiation at an initial pressure of $1 \mathrm{~atm}$. The flame temperature shows a peak at close to stoichiometric concentration. Furthermore, it is evident that a pressure rise will increase the flame temperature as shown in the bottom row. The corresponding influence of the flame temperature on the flame surface emissive flux is discussed in Section 3.1.

\section{Results and Discussion}

\subsection{Flame Radiation}

The spectral radiance from gaseous combustion products from a stoichiometric methane-air flame at $T_{b}=2212 \mathrm{~K}$ and ambient pressure for different path lengths can be seen in Fig. 3 along with the blackbody distribution. Flame radiation will approximate that of a blackbody at large path lengths, Moore and Weinberg (1987) have also reported high emissivities of a stoichiometric propane-air flame at $2000 \mathrm{~K}$ using the same method at $25 \mathrm{~m}$ path length. The absorption bands of carbon dioxide and water vapour overlap at 2.7 and $4.3 \mu \mathrm{m}$, which explains the high emissivity reached in these spectral regions even at short path lengths. Furthermore, it can be seen why laboratory scale flames (i.e. $L=1 \mathrm{~m}$ ) exhibit low emissivity, $\varepsilon_{g}=0.16$ and thus are optically thin. The flame emissivity reaches $\varepsilon_{g}=0.68$ at a path length of $50 \mathrm{~m}$. The path length corresponds to the physical path through the hot combustion products. Due to the thermal expansion, a $50 \mathrm{~m}$ burnt cloud typically corresponds to an unburnt cloud size of less than $10 \mathrm{~m}$. Finkelnburg (1949) has discussed the conditions for blackbody radiation from extensive 


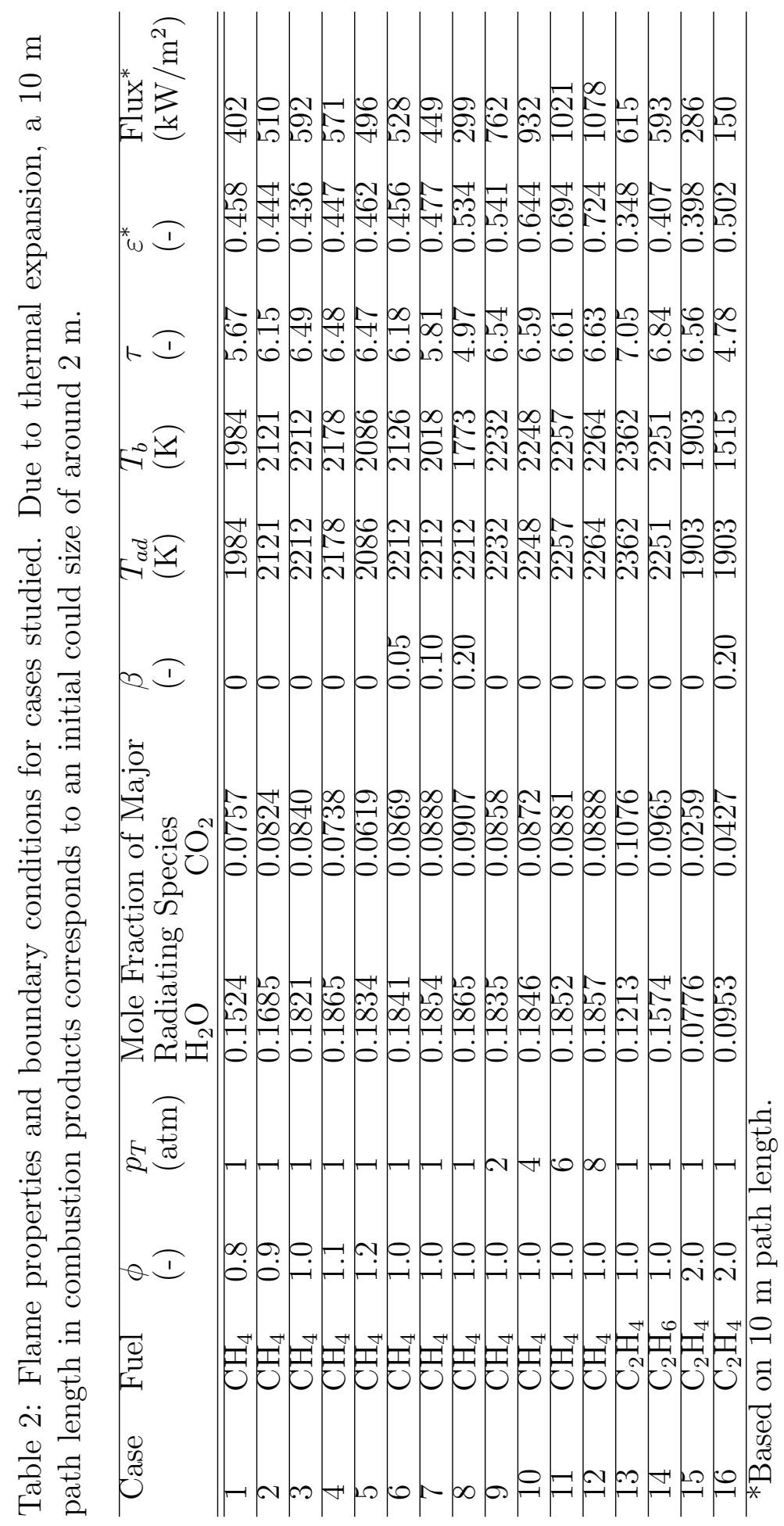


gas masses of equal temperature, one example typically used to corroborate this argument is the continuous spectrum of the sun. In reality, any isothermal gas can potentially emit radiation according to Planck's law which is solely controlled by the absolute temperature given sufficient layer thickness and temperature equilibrium. Reasonable temperature homogeneity is indeed expected in the burnt gas volume which is subject mainly to radiative cooling. This simple analysis shows that a vapour cloud explosion can theoretically approximate a blackbody radiator due to the large gas volumes and elevated temperatures involved.

The effect of mixture stoichiometry, heat loss and pressure were considered for a methane-air mixture from laminar flame calculations. The total mixture emissivity can be seen on the left hand side of Fig. 4 while the corresponding flame surface flux, calculated via Eq. (7), is shown on the right hand side. The flame emissivity remains almost constant with changes in the fuel-air concentration. The resulting flame temperature is a function of the equivalence ratio, hence, the latter has a clear impact on the emitted surface flux which is proportional to the forth power of the temperature. For a methane-air mixture the emissive flux is expected to peak near stoichiometric concentration. Heat losses occurring during combustion influence both the resulting temperature and product concentration. Whilst lower flame temperatures led to higher emissivities, the surface flux is reduced due to the strong temperature dependence.

The spectral radiance of a blackbody will shift to the infrared with decreasing temperature (i.e. $\lambda_{p}=1.64 \mu \mathrm{m}$ at $1773 \mathrm{~K}$ to $\lambda_{p}=1.31 \mu \mathrm{m}$ at $2210 \mathrm{~K}$, where $\lambda_{p}$ is the wavelength peak of the blackbody the spectrum) 
providing a better overlap with the infrared absorption bands of the principal combustion products leading to higher emissivity. In addition, the effect of total mixture pressure is examined in order to account for over-pressures that may occur during the flame propagation. High pressure increases the partial pressure of gaseous combustion products and to a lesser extent the temperature which raises significantly both the emissivity and surface flux. Furthermore, the same mechanism implies that detonation products will become highly emissive. Based on data obtained using GASEQ (Morley, 2013) for a stoichiometric methane-air CJ detonation, assuming unit path length, combustion products can reach an emissivity of 0.40 compared to 0.16 for a deflagration. In addition, the increased temperature observed in a detonation wave will induce a significant increase of the flame surface flux.

The emissivity from other fuels was calculated also for stoichiometric concentration and assuming adiabatic combustion. These, include ethylene and ethane as shown in Fig. 5. Again, the shift of the blackbody distribution to visible wavelengths with increasing temperature is responsible for the lower emissivities observed with more reactive fuels. The flame surface flux is similar for all mixtures because temperature and emissivity counter interact each other. For the case of a path length of $50 \mathrm{~m}$ the corresponding difference in the magnitude of flame surface flux obtained with different fuels is less than $10 \%$. Carbon dioxide absorption bands (i.e. $2.7 \mu \mathrm{m}, 4.3 \mu \mathrm{m}$ and $15 \mu \mathrm{m}$ ) saturate at much shorter path lengths than the corresponding water bands. Additionally, at wavelengths shorter than $2.7 \mu \mathrm{m}$ radiation is emitted only by water molecules, this coincides with the peak blackbody distribution at such flame temperatures $\left(\lambda_{p}=1.27 \mu \mathrm{m}\right)$. This observation leads to the con- 
clusion that hydrocarbon compounds with more hydrogen atoms will cause saturation at shorter path lengths given similar flame temperatures.

The emissivity from a rich ethylene-air flame $(\phi=2.0)$ is shown in Fig. 6 . This equivalence ratio is above the sooting limit and a modest soot volume fraction of $1 \times 10^{-7}$ is included in the analysis. The gaseous emissivity is computed using the method described above using data from laminar flame calculation at adiabatic conditions. The emissivity of soot has been obtained from Eqs. (1) and (4) using the soot-emission parameter $\left(k_{s}\right)$ from Yuen and Tien (1977). The emissivity of a gas-soot mixture is of the same order as that of the gas alone for path lengths below $0.1 \mathrm{~m}$, as the path length increases, the combined emissivity rises steeply reaching almost unity at $10 \mathrm{~m}$.

Furthermore, the influence of the temperature and soot concentration on the corresponding emissivity of a gas-soot mixture can be seen in Fig. 7. The temperature sensitivity was carried out by comparing the adiabatic ethyleneair case $(\phi=2.0)$ with one that included $20 \%$ heat loss. In addition, three soot volume fractions have been included in each mixture that relate to a low, moderate and high soot concentrations (Geitlinger et al., 1998; DeIuliis et al., 1998; McEnally et al., 1997; Nathan et al., 2012; Wal and Weiland, 1994). Unit emissivities are reached around $0.1 \mathrm{~m}$ path length with $f_{v}=1.0 \times 10^{-5}$ compared to $10 \mathrm{~m}$ with $f_{v}=1.0 \times 10^{-7}$ at the same temperature. The flame temperature also affects the mixture emissivity but to a lesser extent. The combined emissivity at a fixed path length depends on the soot-emission parameter $\left(k_{s}\right)$ which is directly proportional to both the temperature and soot volume fraction. Flame temperatures vary by a few hundreds degrees, however, the soot volume fraction can vary by orders of magnitude, hence, it 
can greatly impact the total emissivity. The extreme case of $20 \%$ heat loss which led to a flame temperature of $1515 \mathrm{~K}$ has been specifically selected to highlight the comparatively weak dependence on temperature. Therefore, in a real incident, soot will ultimate lead to higher emissivity at much shorter path lengths, irrespective of the overall temperature. Of course, in case of a stratified cloud featuring local temperature inhomogeneities the overall radiative heat emitted will be a superposition over the total flame surface.

\subsection{Forward Thermal Radiation}

In order to calculate the radiation received by particles ahead of the flame front, the flame surface flux has to be estimated first. Assuming that the flame front radiates like a solid radiator the emitted heat flux will strongly depend on the temperature of the combustion products as outlined above. The maximum surface radiation flux expected for different flame temperatures and emissivities obtained from Eq. (7) is shown in Fig. 8. Note that the flame surface flux corresponds to the emitted power density rather than the heat transferred to a potential target and is therefore a function of the radiator temperature only. For a stoichiometric methane-air mixture at ambient pressure the burned products would be at $T_{b}=2212 \mathrm{~K}$. It can be deduced that surface fluxes ranging from $1350 \mathrm{~kW} / \mathrm{m}^{2}$ for $\varepsilon_{f}=1.0$ to $810 \mathrm{~kW} / \mathrm{m}^{2}$ for $\varepsilon_{f}=0.6$ can be expected.

The spatial variation of the ratio of the incident to source flux $\left(I / I_{\mathrm{O}}\right)$ due to the absorption from unburned gas mixture (including the presence of water vapour and carbon dioxide), obtained from Eq. (8), for three product temperatures is shown in Fig. 9. As the blackbody temperature decreases, the spectral radiance shifts towards the infrared providing a better overlap 
with the infrared absorption bands of the fuel-air mixture and, hence, higher attenuation is observed. Nevertheless, even at the limiting case of $2000 \mathrm{~K}$ the attenuation remains at 10 and $25 \%$ at 10 and $25 \mathrm{~m}$ from the flame front, respectively. This suggests that attenuation from the unburned gas mixture is not appreciable up to $10 \mathrm{~m}$ from the main flame front which is the order of length scale of interest.

The radial irradiance field assuming an average unburned cloud depth of $2 \mathrm{~m}$ and an isobaric expansion coefficient of 6 is shown in Fig. 10a. The products were modelled as a squat cylinder and the receptor was assumed to be on the ground. Due to thermal expansion, a burnt cloud height of 12 $\mathrm{m}$ corresponds to an unburnt cloud depth of approximately $2 \mathrm{~m}$. A flame temperature of $2212 \mathrm{~K}$ and unit emissivity was selected as a representative of a stoichiometric methane-air mixture. As the flame propagates radially into the unburned gas mixture, the products approximate larger characteristic ratios (i.e. $\mathrm{R} / \mathrm{H} \geq 5$ ) increasing the level of irradiance received by particles. Therefore, the magnitude of flux will depend on the surface area of the source (i.e. the radius of the products) highlighting the specific application to vapour cloud explosions. Also, off the ground particles may receive different irradiance.

The distribution of irradiance in the unburned region as a function of the distance between the particle and flame front can be seen in Fig. 10b. As shown in Fig. 8, the flame surface flux expected from a stoichiometric product cloud of unit emissivity is around $1350 \mathrm{~kW} / \mathrm{m}^{2}$. The squat cylinder model used (Mudan, 1987) predicts lower irradiance close to the burnt cloud edge. This is a geometric effect due to the curvature of the cylinder and the 
fact that the receptor is assumed to be located on the ground, which causes attenuation in the near field. Assuming a characteristic ratio of $\mathrm{R} / \mathrm{H}=1$, irradiance greater than $250 \mathrm{~kW} / \mathrm{m}^{2}$ can be expected up to a distance of $10 \mathrm{~m}$ ahead the flame front. As the burned products grow radially, they approximate higher $\mathrm{R} / \mathrm{H}$ ratios and the same level of irradiance $\left(250 \mathrm{~kW} / \mathrm{m}^{2}\right)$ can be received up to $25 \mathrm{~m}$ ahead of the flame. The first 10 to $25 \mathrm{~m}$ into the unburned gas mixture is critical for the short length and time scales required for radiation to have an impact on the overall flame propagation. Beyond this region, lower irradiance is expected reducing the possibility of a kernel forming within a reasonable ignition time. Nevertheless, it has been shown that the radiation levels obtained from the above analysis are sufficient to ignite a fuel-air mixture (Beyrau et al., 2013). In particular, ignition time scales $\simeq 100 \mathrm{~ms}$ at an irradiance $<600 \mathrm{~kW} / \mathrm{m}^{2}$ were obtained using substrates coated with a commercially available carbon black powder (acetylene black) in a stoichiometric butane-air mixture. For length scales larger than $10 \mathrm{~m}$, absorption by the fuel-air mixture may become important. However, as shown earlier the effect is small compared to that of the view factor.

Whilst the types of particles examined by Beyrau et al. (2013) may be present in industrial facilities, the ignition times alone do not prove that radiative induced ignition can occur. As shown above, the level of irradiance posed on such particles cannot be spatially uniform across the reactants since, the irradiance will attenuate with distance from the main flame front due geometric effects and possibly due to absorption from the intervening medium. In practical vapour cloud incidents, the plausibility of formation of local exothermic centres ahead of the flame will depend on the time to 
ignition which is determined by the level of irradiance and, hence, on the distance from the flame front. In order to have a notable effect, particles have to be ignited before the advancing flame consumes them. Therefore there are likely to be influences from (i) the average rate of flame propagation, (ii) the location (relative the advancing flame front), (iii) the density of the suspended particles in the unburnt region and (iv) the lower flame surface flux due to convective and radiative losses. The flame speed is a key parameter as it will influence the thermal dose received a particle as well as the duration of the irradiation before it is consumed by the propagating flame. Nevertheless, the current study shows that the estimated and required irradiances are comparatively close and hence, the flame propagation mechanism proposed by Atkinson and Cusco (2011) cannot currently be ruled out.

Moreover, Fig. 11 shows a comparison with other radiation heat transfer models, that of coaxial disks and squares, which are more appropriate for confined geometries. In these coaxial models, the vertical coordinate of the target is linked with the source size (i.e. burned gas height) which is not a realistic assumption for heavy vapour clouds. A squat cylinder is a more suitable for representing unconfined systems as considered in the current study. Nevertheless, these models can be used to highlight further the importance of the source size. From a heat transfer point of view, the radiation emitted from a modest (e.g. laboratory) scale solid radiator with unit area (i.e. $L_{\text {char }}=1 \mathrm{~m}$ ) will, even with unit emissivity, attenuate simply due to geometric factors at a distance of $2-3 \mathrm{~m}$ from the source. Distributions predicted using the model of coaxial squares are slightly higher than those obtained using the coaxial disks model. This, of course, is expected since 
a larger emitting area is taken into account when a square is used. Also, the coaxial models predict higher irradiance near the flame front and lower irradiance in the far field compared to the squat cylinder. Again, this is expected since the curvature of the cylinder causes a geometric attenuation in the near field while in the far field, the surface area of the squat shape is overall larger than the symmetric ones.

Another point that can be raised is the effect of flame area enhancement due to turbulence. The total forward thermal radiation is proportional to the emitting area $\left(A_{1}\right)$ as shown in Eq. (5). In the above analysis, the flame has been modelled as smooth surface which is arguably not accurate since a turbulent flame front will be wrinkled. Gouldin (1987) and Gouldin et. al. (1989) have proposed that the area of flamelet surfaces in turbulent flames can be estimated using fractals. Fractal surfaces are characterised by selfsimilarity over wide range of scales (Mandelbrot, 1982) and hence, allow the explicit consideration of multi-scale wrinkling. Turbulence will increase the ensemble-average flame area by an enhancement factor,

$$
\frac{A_{1}}{A_{o}}=\left(\frac{L_{I}}{L_{K}}\right)^{D-2}
$$

where $A_{1} / A_{o}$ is the ratio of the areas at the inner and outer cutoffs, $L_{I}$ is the integral length scale, $L_{K}$ the Kolmogorov length scale and $D$ the fractal dimension. The ratio of the integral and Kolmogorov length scales follows,

$$
\frac{L_{I}}{L_{K}}=R e_{T}^{3 / 4}
$$

where $R_{T}$ is the turbulence Reynolds number. Assuming a mean fractal 
dimension of 7/3 (Gülder, 1990; Kerstein, 1988), the flame surface enhancement factor can be expressed as a function of $R e_{T}$.

$$
\frac{A_{1}}{A_{o}}=R e_{T}^{1 / 4}
$$

The influence of the turbulence Reynolds number on the flame surface enhancement factor is shown in Table 3, The results suggest a significant increase at high turbulence Reynolds numbers. Hence, turbulence can be expected to enhance the overall heat transfer, though the local flame surface characteristics may affect the corresponding view factor. Moreover any spatial inhomogeneities in the temperature or the concentration of the combustion products will influence the corresponding flame surface flux.

Table 3: The influence of the turbulence Reynolds number on the flame surface enhancement factor.

\begin{tabular}{ll}
\hline$R e_{T}$ & $A_{1} / A_{O}$ \\
\hline \hline 1 & 1 \\
10 & 1.79 \\
100 & 3.16 \\
1000 & 5.62 \\
\hline
\end{tabular}

The fuel dependency on the distribution of irradiance from a square source $\left(L_{c h a r}=10 \mathrm{~m}\right)$ as function of the distance from the flame front is shown in Fig. 12. Assuming unit emissivity and adiabatic flame temperatures obtained earlier using laminar flame calculations, the forward thermal radiation from methane, ethane and ethylene flames can be estimated. The flame temperature will influence both the maximum intensity and the corresponding distribution of irradiance over a given distance. Hence, in practical incidents the level of irradiance expected on particles likely to be present ahead of the 
propagating front will strongly depend on the fuel type.

Finally, while not of direct relevance to the current study, radiation from a detonation event may be estimated for comparison purposes. For example, a stoichiometric methane-air CJ detonation yields a temperature of $2767 \mathrm{~K}$ and pressure of 16.6 atm (Morley, 2013) and the peak irradiance is estimated $3350 \mathrm{~kW} / \mathrm{m}^{2}$. A detonation event is indeed expected to be highly emissive as discussed earlier. Although not presented here, it is estimated that radiation levels higher than $820 \mathrm{~kW} / \mathrm{m}^{2}$ can be readily obtained $10 \mathrm{~m}$ ahead of a local detonation event $(\mathrm{R} / \mathrm{H}=1)$ for an unburnt cloud height of $2 \mathrm{~m}$.

\section{Conclusions}

A study has been performed in order to estimate the radiation levels expected from flame fronts appearing as part of vapour cloud explosions and to examine the corresponding forward thermal radiation posed on particles in the unburnt part of the cloud. The radiation emitted from the principal gaseous products $\mathrm{H}_{2} \mathrm{O}$ and $\mathrm{CO}_{2}$ at large optical path lengths has been estimated and a sensitivity analysis performed to assess the impact of variations in the equivalence ratio, mixture pressure and radiative heat losses. It has ben shown that the flux from the gas phase is expected to peak near a stoichiometric concentration due to the strong temperature dependence. It has also been shown that in the presence of soot, high flame emissivities can been achieved at path lengths of the order $1 \mathrm{~m}$ and that the emissivity of gas-soot mixture will be mainly determined by the soot concentration and to a lesser extent by the mixture temperature. Hence, in a real incident, fuel-air mixtures prone to soot formation will ultimately yield higher thermal radiation at 
short path lengths. In summary, the distribution of irradiance on particles suspended ahead of a flame front will strongly depend on the presence of any soot, the flame temperature and, to a lesser extent, the burnt gas composition. Assuming a stoichiometric, squat methane-air cloud of unit emissivity and a characteristic ratio $\mathrm{R} / \mathrm{H}=10$, irradiance greater than $250 \mathrm{~kW} / \mathrm{m}^{2}$ can be expected up to a distance of $25 \mathrm{~m}$ from the flame front without accounting for any area enhancement caused by turbulence. Radiation levels $\sim 600 \mathrm{~kW} / \mathrm{m}^{2}$, necessary for sufficiently short ignition time scales (Beyrau et al., 2013), can be readily obtained for distances up to $8 \mathrm{~m}$ from the flame front. The estimated and required fluxes are comparatively close and, hence, the episodal flame propagation mechanism proposed by Atkinson and Cusco (2011) cannot currently be ruled out.

\section{Acknowledgements}

F. Beyrau, M.A. Hadjipanayis and R.P. Lindstedt are grateful for the financial support provided by the Health \& Safety Laboratory of the Health and Safety Executive. The authors are indebted to Hans Michels and Bob Simpson for their helpful advice. The authors would also like to thank Fabian Hampp for his assistance with the laminar flame calculations. 


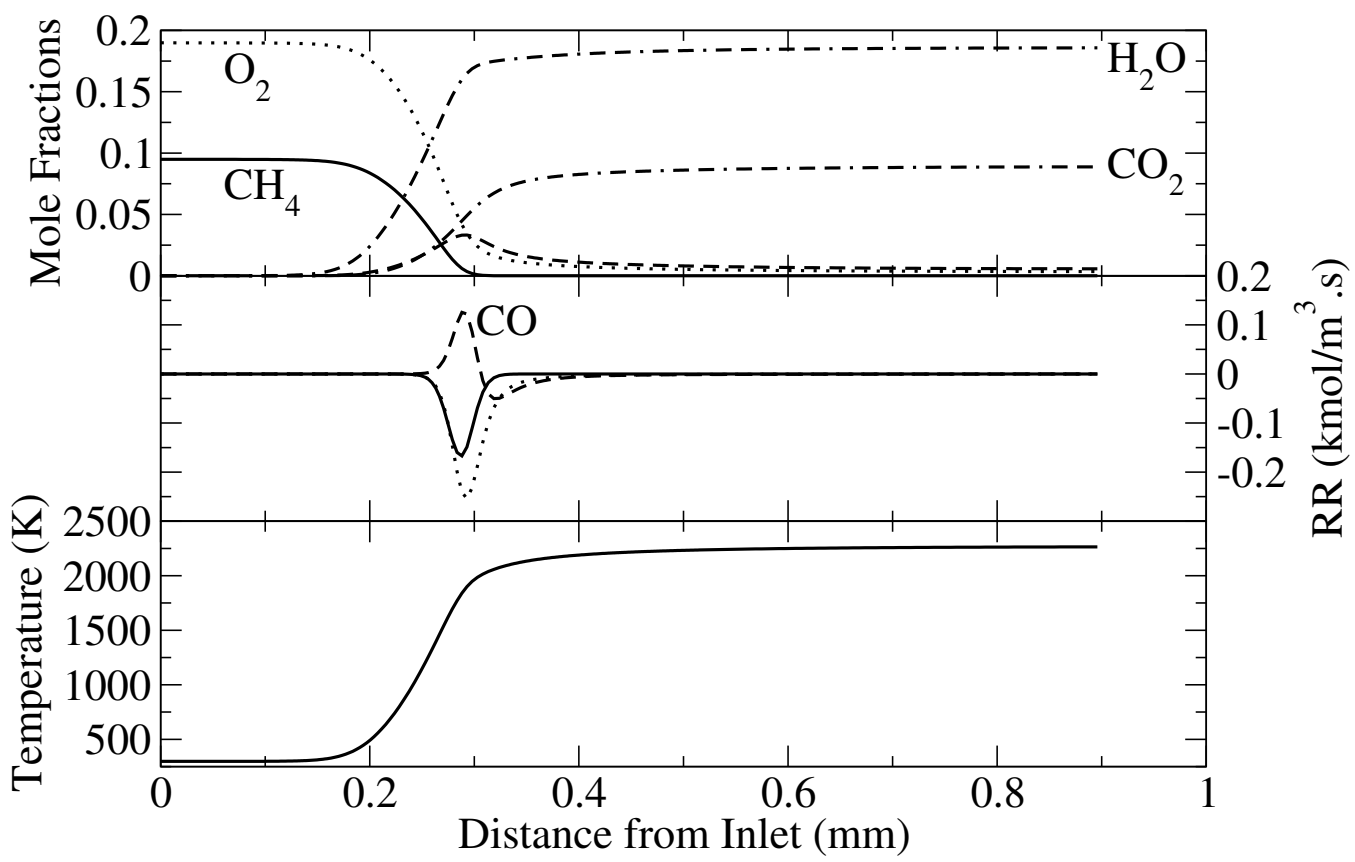

Fig. 1: Sample laminar flame calculation for a stoichiometric methane-air mixture, $T_{i}=298 \mathrm{~K}, p_{T}=8$ atm. Top: Species concentration $\left(\mathrm{CH}_{4}, \mathrm{O}_{2}\right.$, $\mathrm{H}_{2} \mathrm{O}, \mathrm{CO}_{2} \mathrm{CO}$ ); Middle: The corresponding reaction rates for $\mathrm{CH}_{4}, \mathrm{O}_{2}$ and $\mathrm{CO}$; Bottom: Temperature profile. 


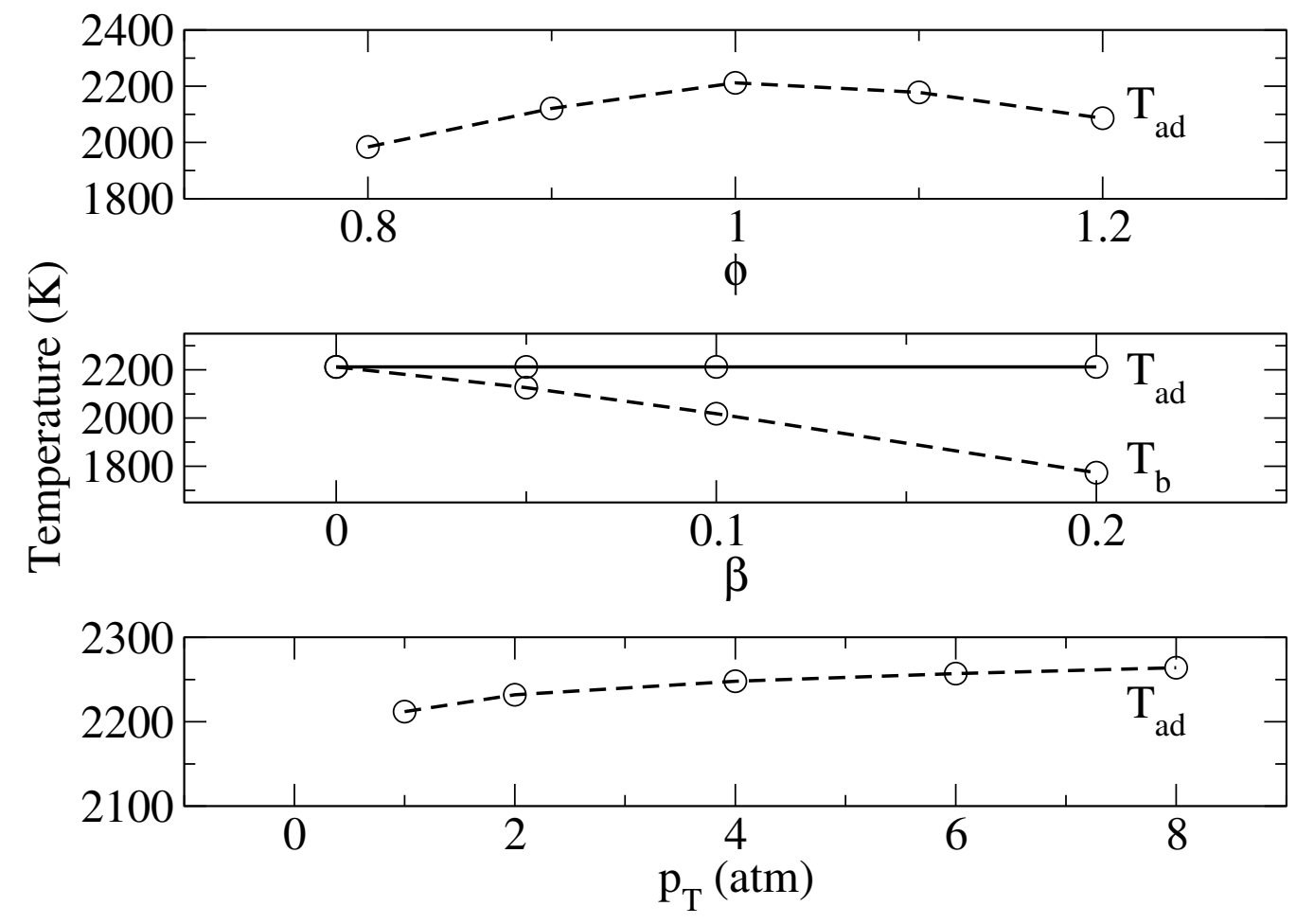

Fig. 2: Flame temperatures for all methane-air mixtures examined, $T_{i}=298 \mathrm{~K}$. The corresponding flame properties for selected cases can be found in Table 2. Top: Influence of mixture stoichiometry; Middle: Influence of radiation losses; Bottom: Influence of total pressure. 


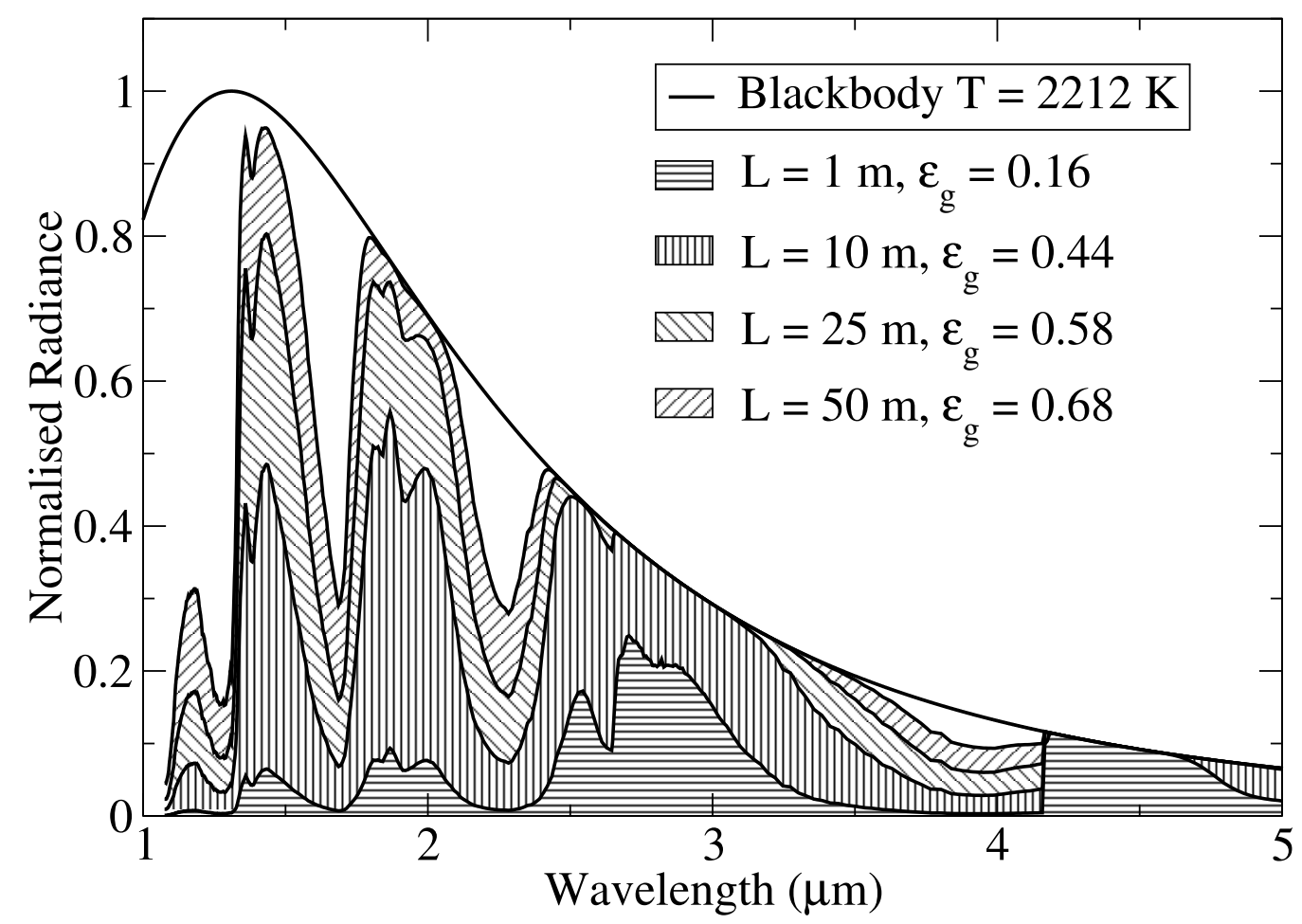

Fig. 3: Normalised spectral radiance of principal combustion products of a stoichiometric methane-air flame $\left(T_{b}=2212 \mathrm{~K}\right)$ along with blackbody at $2212 \mathrm{~K}$ for comparison. Partial pressure of principal combustion products: $\mathrm{p}_{\mathrm{H}_{2} \mathrm{O}}=0.182 \mathrm{~atm}, \mathrm{p}_{\mathrm{CO}_{2}}=0.084 \mathrm{~atm}, \mathrm{f}_{\mathrm{v}}=0$. 

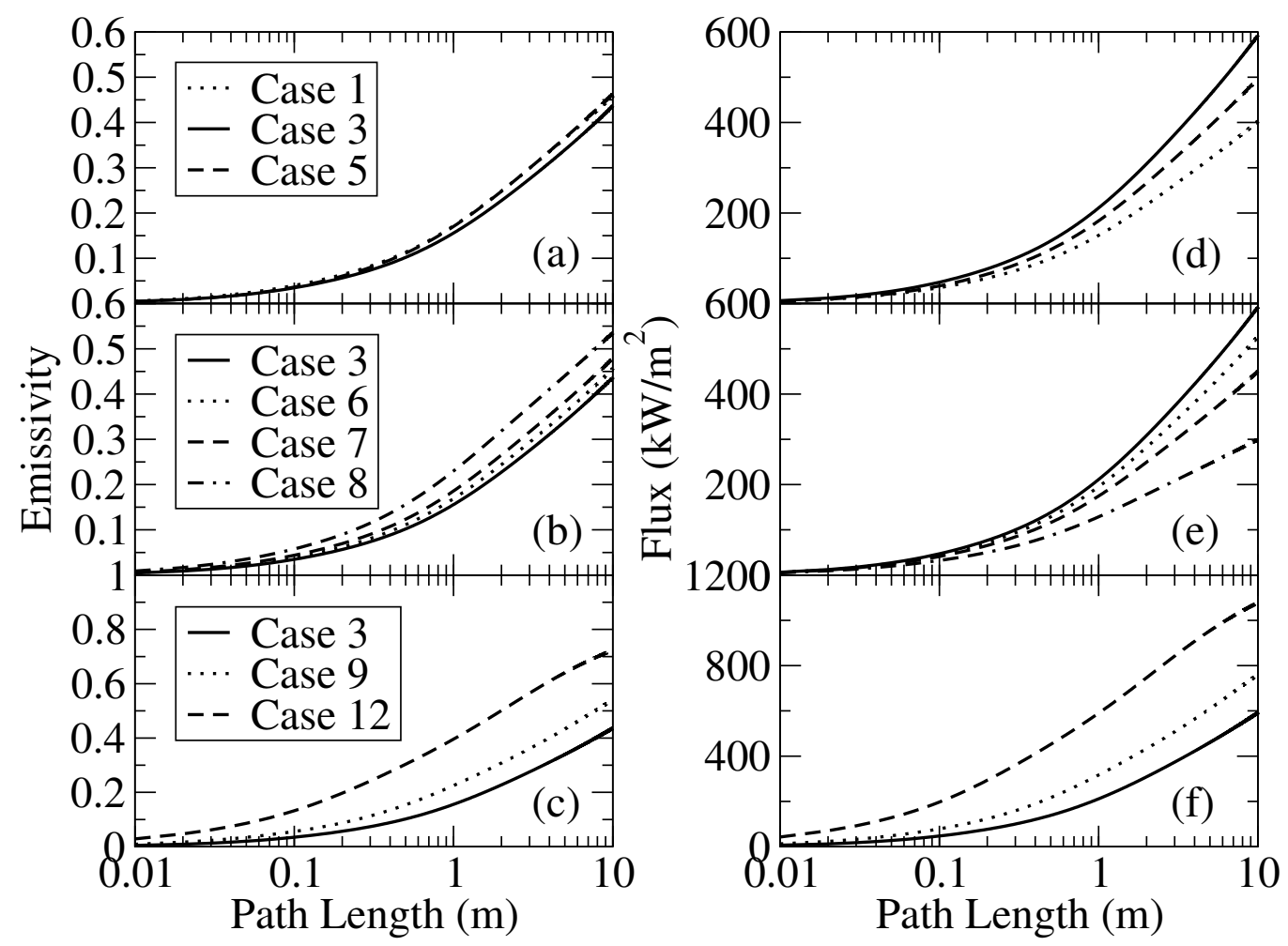

Fig. 4: Total emissivity and surface emissive flux from a methane-air flame as a function of the path length. Top: Influence of mixture stoichiometry; Middle: Influence of radiation losses; Bottom: Influence of total pressure. The corresponding flame properties for selected cases can be found in Table 2 . 


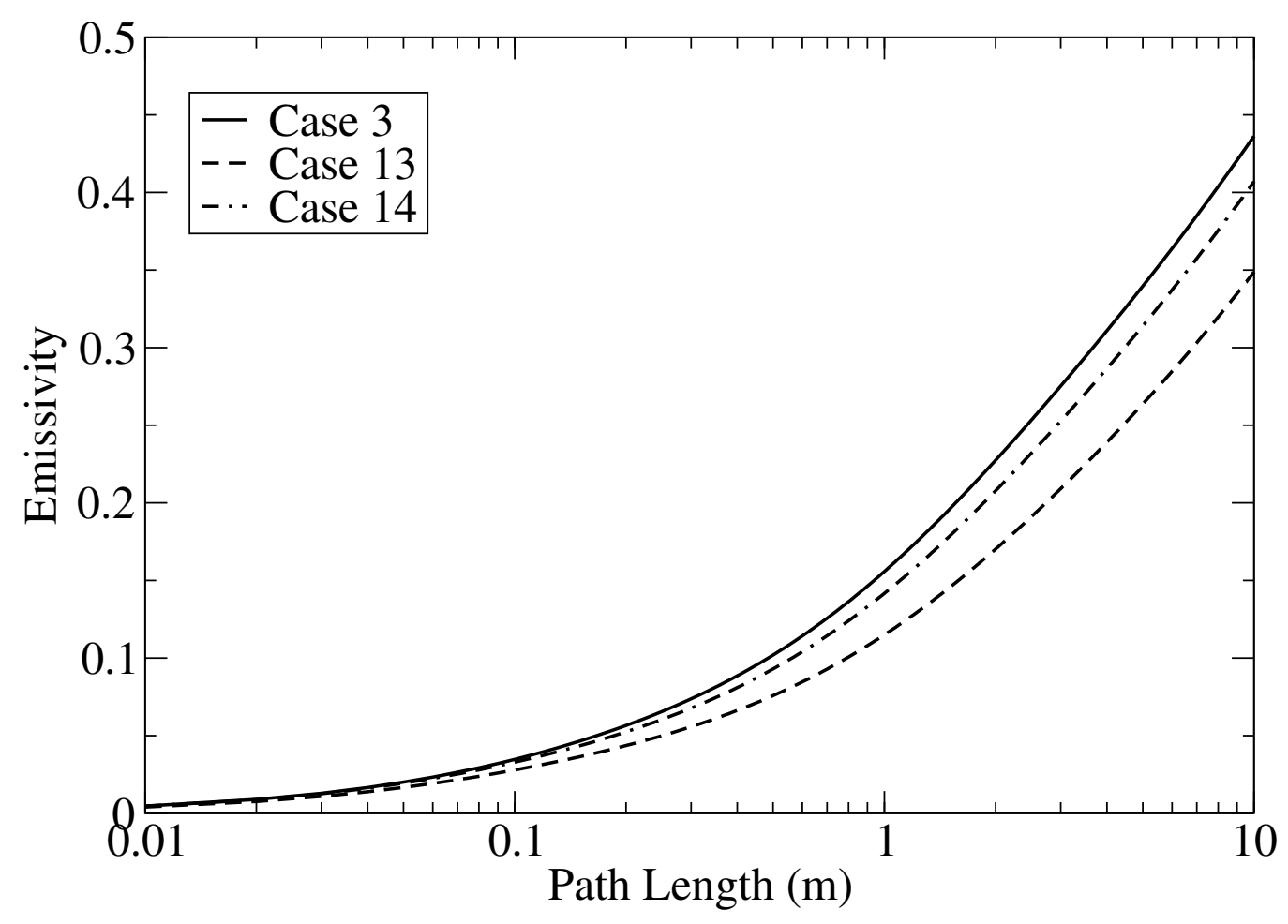

Fig. 5: The influence of the fuel type on the total emissivity for selected stoichiometric fuel-air mixtures as a function of the path length at total pressure, $p_{T}=1 \mathrm{~atm}$. The corresponding flame properties for selected cases can be found in Table 2 . 


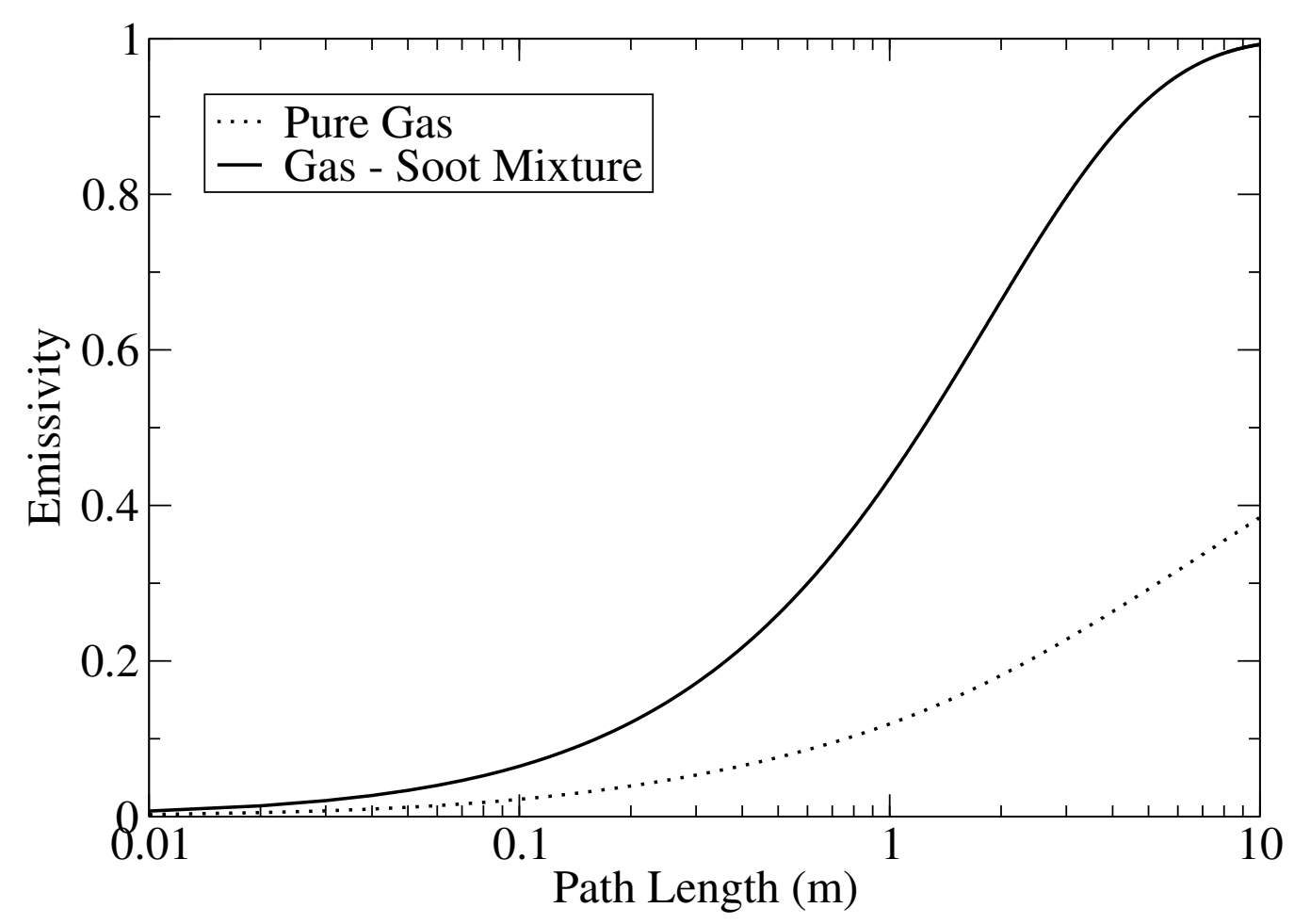

Fig. 6: Total emissivity of homogeneous $\mathrm{H}_{2} \mathrm{O}-\mathrm{CO}_{2}$-soot mixture obtained from an ethylene-air flame $\left(\phi=2.0, T_{b}=1903 \mathrm{~K}, f_{v}=1.0 \times 10^{-7}\right)$ as a function of the path length. The corresponding flame properties for Case 15 can be found in Table 2 . 


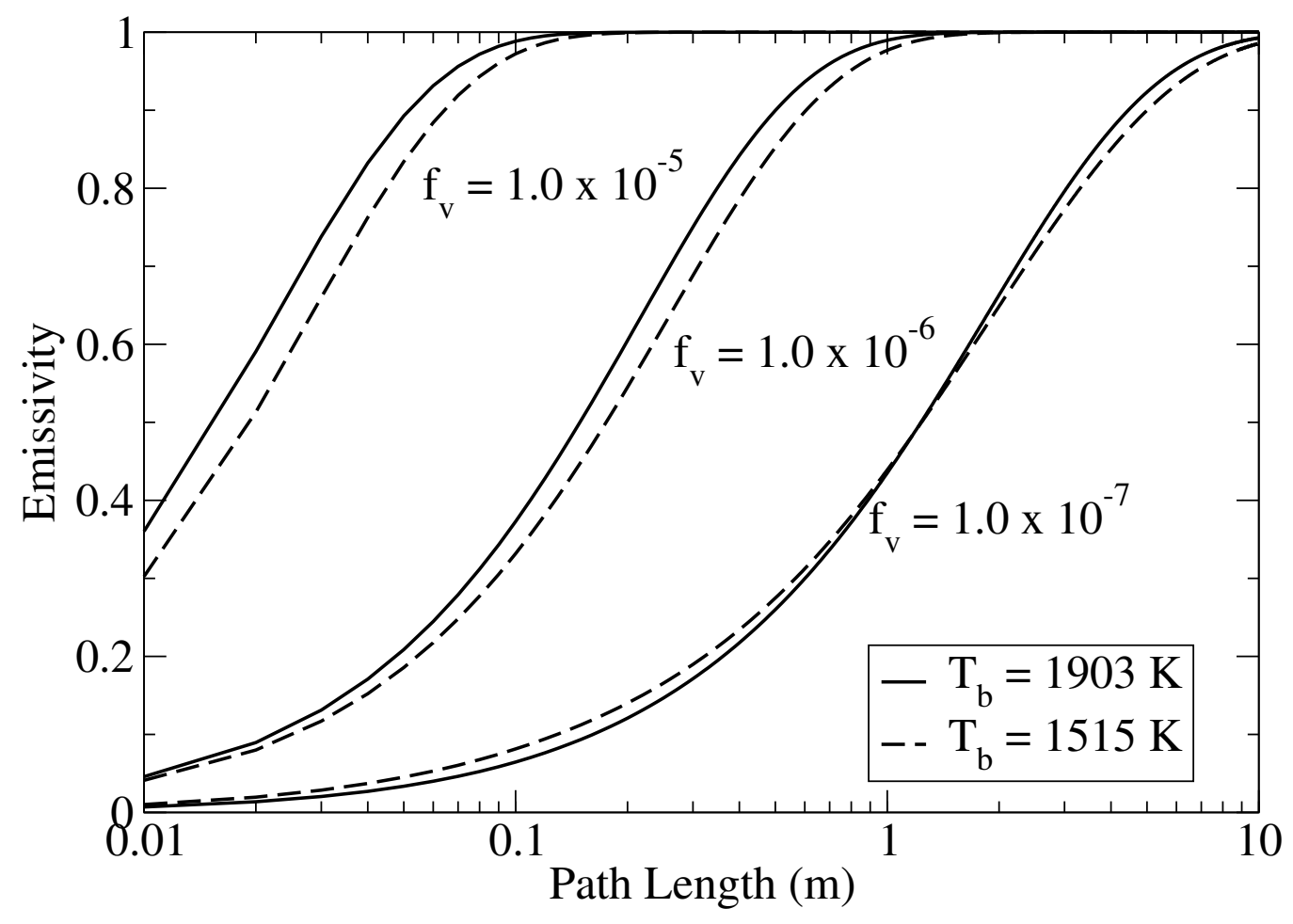

Fig. 7: The influence of combustion heat losses and soot volume fraction $\left(f_{v}\right)$ on the total emissivity of homogeneous $\mathrm{H}_{2} \mathrm{O}-\mathrm{CO}_{2}$-soot mixture as a function of the path length. Case $15(-)$ and 16 (--) from Table 2 have been considered corresponding to a rich ethylene-air flame of 0 and $20 \%$ heat loss respectively. 


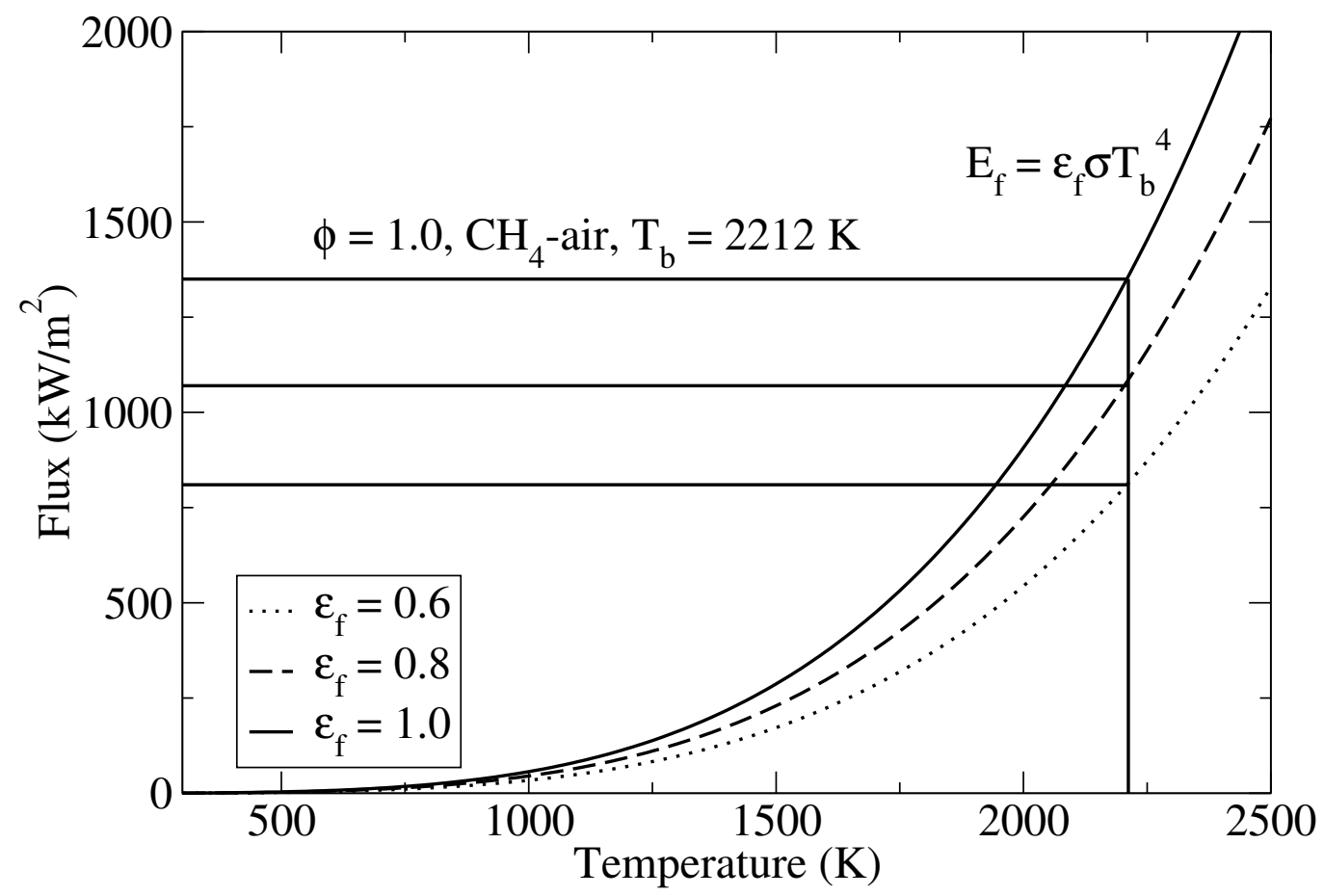

Fig. 8: Surface emissive flux as a function of the flame temperature for different emissivities. Note that the surface emissive flux corresponds to the emitted power density rather than the heat transferred to a potential target, thus is a function of the radiator temperature only. 


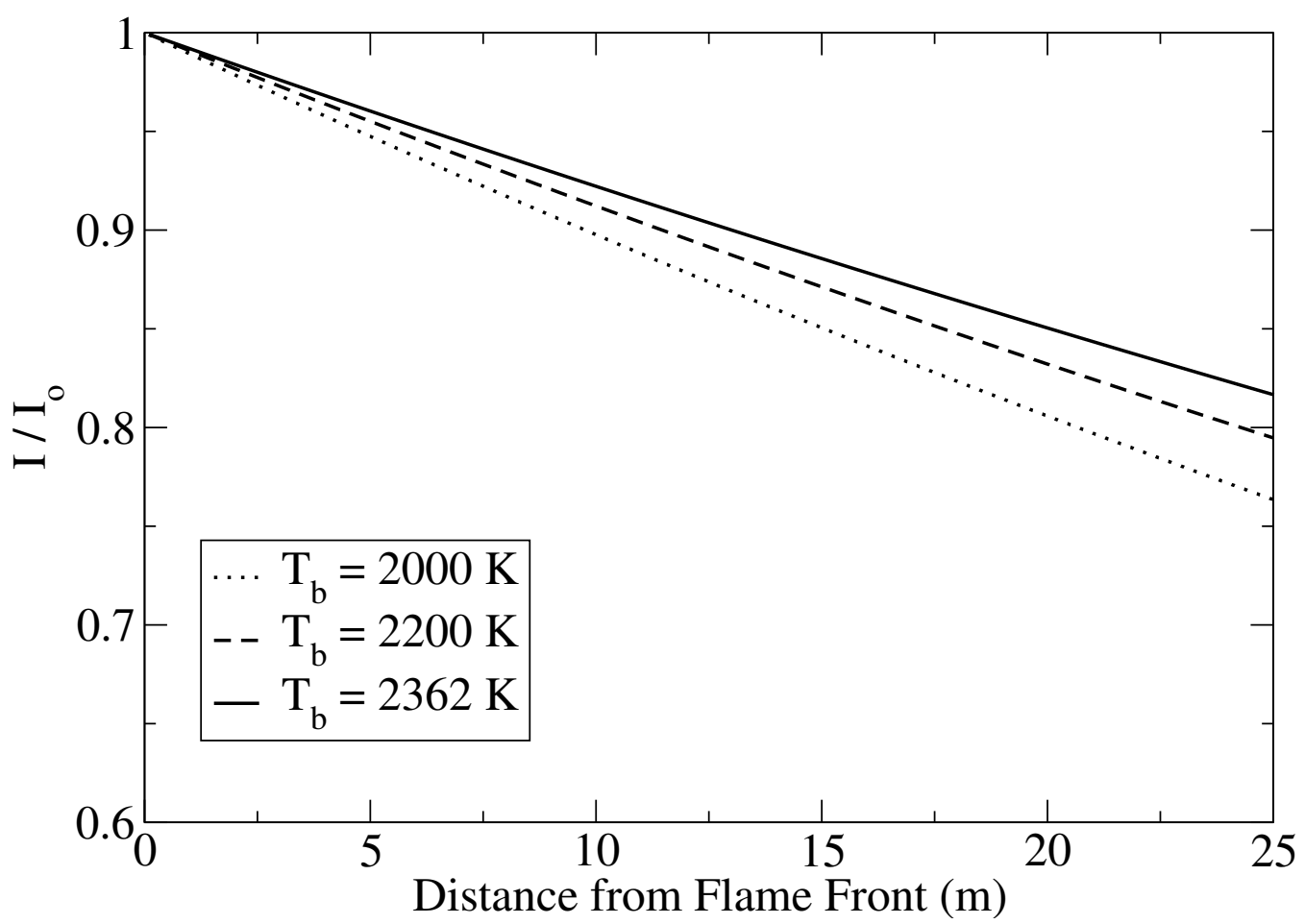

Fig. 9: The ratio of the incident to source flux $\left(I / I_{\mathrm{O}}\right)$ transmitted through a fuel-air mixture for different product cloud temperatures. Conditions: collimated blackbody radiation into a stoichiometric ethylene/air mixture at 1 atm, $298 \mathrm{~K}$ and $100 \%$ humidity. 

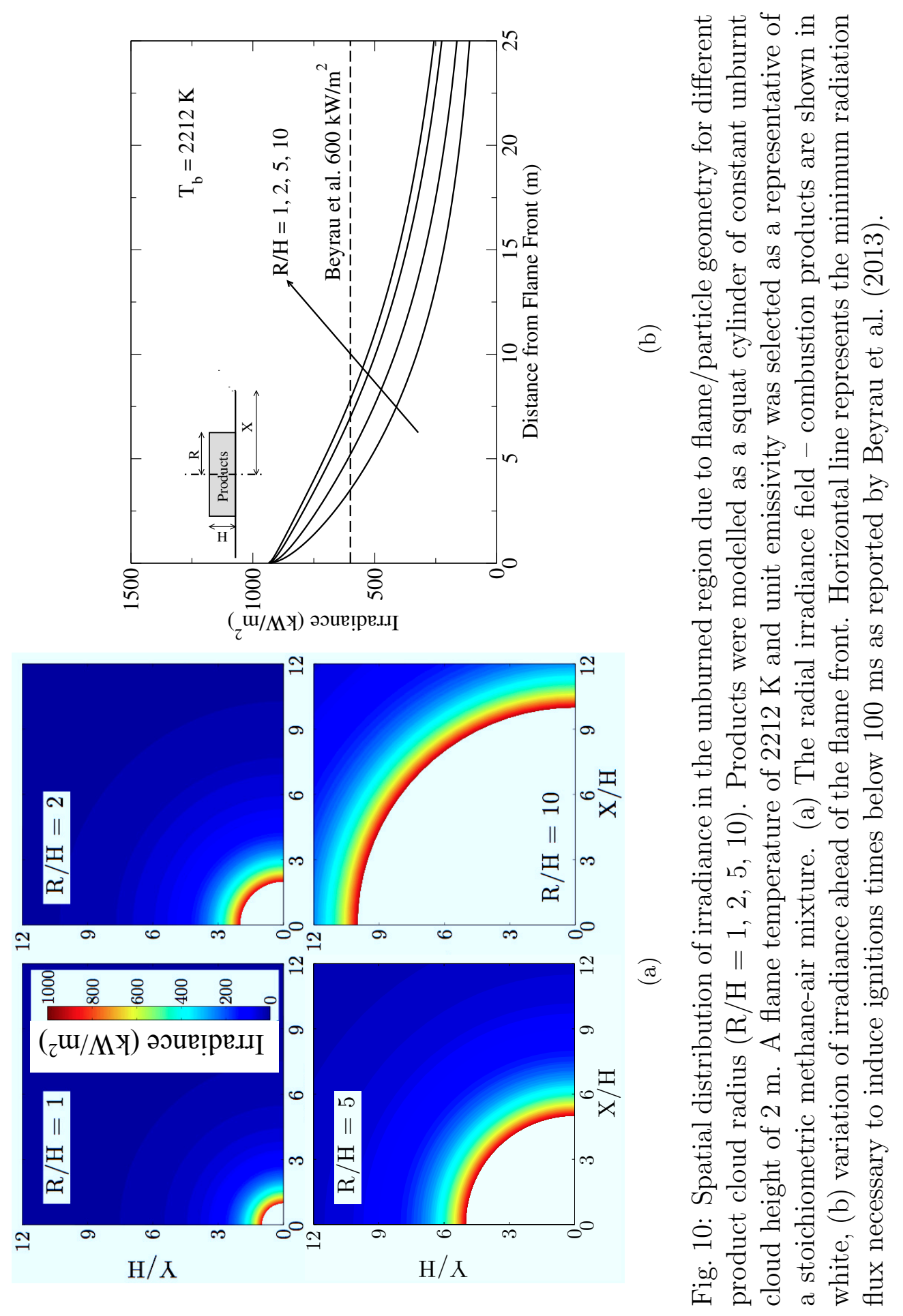


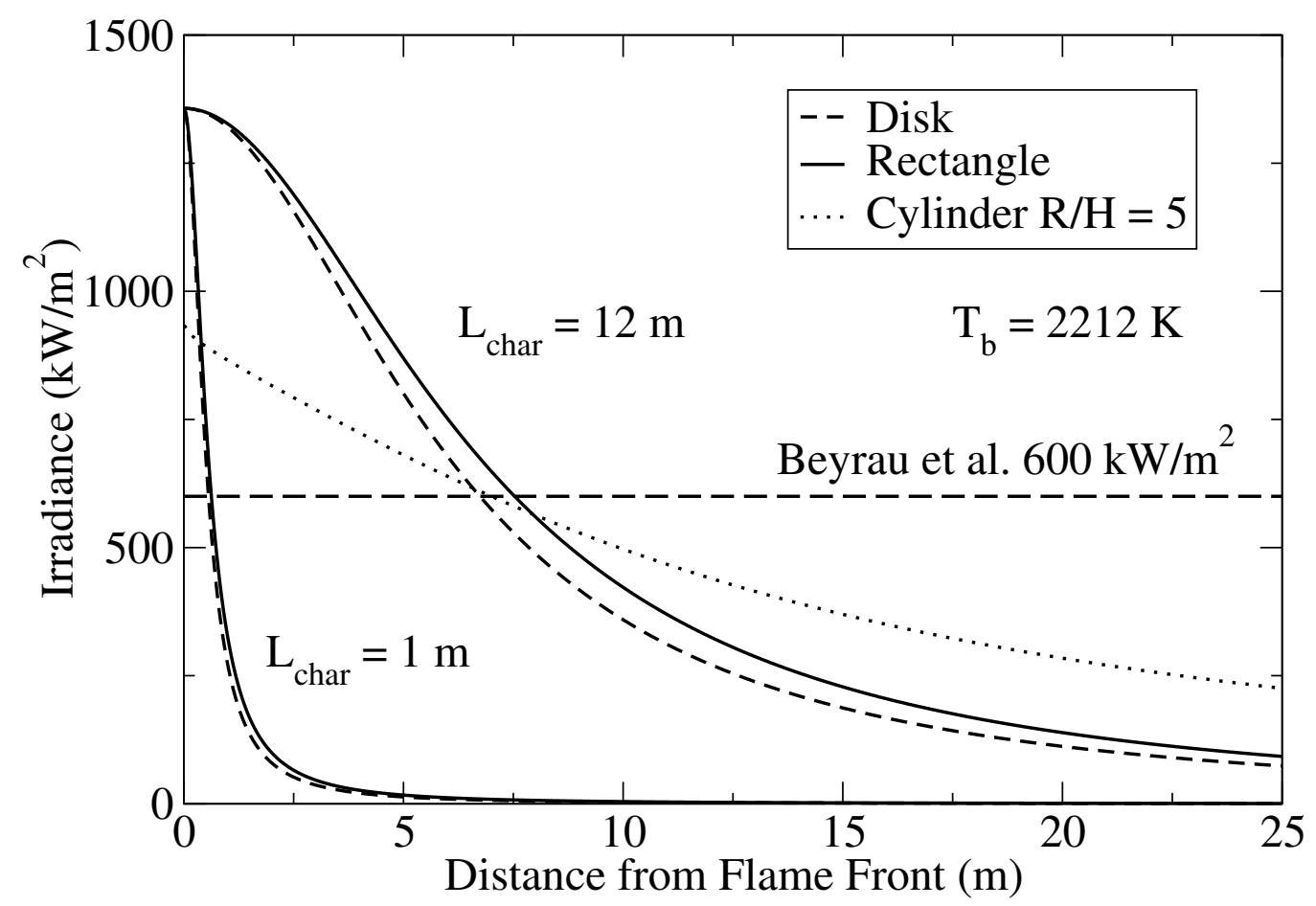

Fig. 11: Spatial distribution of irradiance in the unburned region due to flame/particle geometry. Flame modelled as a straight cylinder, and planar circular and square surface. A flame temperature of $2212 \mathrm{~K}$ and unit emissivity was selected as a representative of a stoichiometric methane-air mixture. Horizontal line represents the minimum radiation flux necessary to induce ignitions times below $100 \mathrm{~ms}$ as reported by Beyrau et al. (2013). 


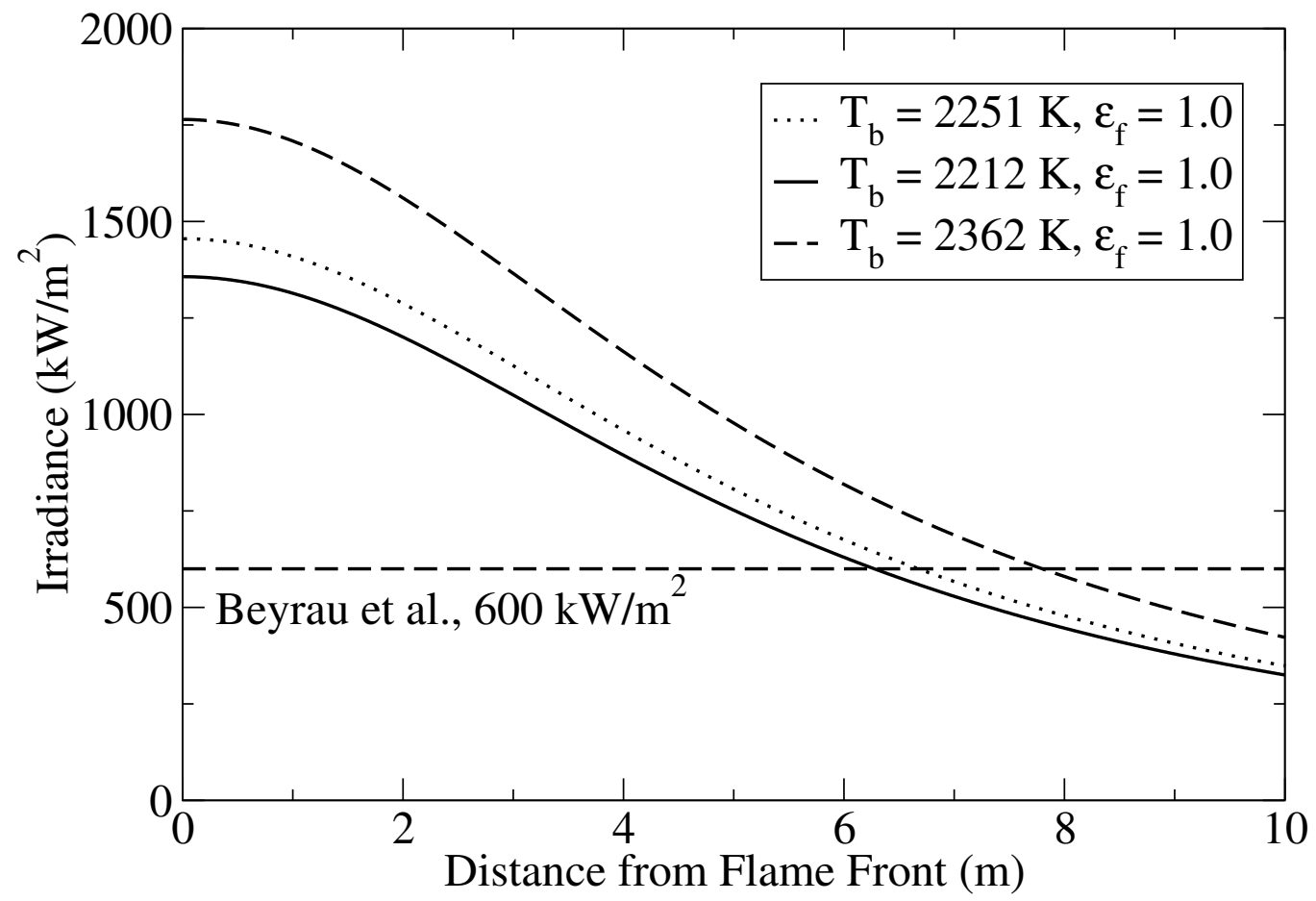

Fig. 12: The influence of the fuel type on the spatial distribution of irradiance in the unburned region due to flame/particle geometry. Case $3(-)$, $13(--)$ and $14(\cdots)$ from Table 2 have been considered, corresponding to a stoichiometric methane, ethane and ethylene-air mixture respectively. Flame modelled as a square source $\left(L_{\text {char }}=10 \mathrm{~m}\right)$. Horizontal line represents the minimum radiation flux necessary to induce ignitions times below $100 \mathrm{~ms}$ as reported by Beyrau et al. (2013). 


\section{References}

Amyotte, P. R., 2006. Solid inertants and their use in dust explosion prevention and mitigation. J. Loss Prevent. Proc. 19 (2-3), 161-173.

Atkinson, G., Cusco, L., 2011. Buncefield: A violent, episodic vapour cloud explosion. Process Saf. Environ 89 (6), 360-370.

Beyrau, F., Hadjipanayis, M. A., Lindstedt, R. P., 2013. Ignition of fuel/air mixtures by radiatively heated particles. Proc. Combust. Inst. 34 (2), 20652072 .

Beyrau, F., Hadjipanayis, M. A., Lindstedt, R. P., (2014). Time-resolved temperature measurements for inert and reactive particles in explosive atmospheres. Proc. Combust. Inst. (on line publication complete) http://dx.doi.org/10.1016/j.proci.2014.06.057.

Davis, B. C., Bagster, D. F., 1989. The computation of view factors of fire models: 1. differential targets. J. Loss Prevent. Proc. 2 (4), 224-234.

Dalzell, W. H., Sarofim, A. F., 1969. Optical Constants of Soot and Their Application to Heat-Flux Calculations. J. Heat Transfer. 91 (1), 100-104.

De Iuliis, S., Barbini, M., Benecchi, S., Cignoli, F., Zizak, G., 1998. Determination of the soot volume fraction in an ethylene diffusion flame by multiwavelength analysis of soot radiation. Combust. Flame 115 (1-2) 253261.

Dorofeev, S. B., Sidorov, V. P., Kuznetsov, M. S., Dvoinishnikov, A. E., 
Alekseev, V. I., Efimenko, A. A., 1996. Air blast and heat radiation from fuel-rich mixture detonations. Shock Waves 6 (1).

Fairweather, M., Jones, W. P., Lindstedt, R. P., 1992. Predictions of radiative transfer from a turbulent reacting jet in a cross-wind. Combust. Flame 89 (1), 45-63.

Fedorov, A. V., 2004. Mixing in wave processes propagating in gas mixtures (review). Combustion, Explosion and Shock Waves 40 (1), 17-31.

Finkelnburg, W., 1949. Conditions for blackbody radiation of gases. J. Opt. Soc. Am. 39 (2), 185-186.

Geitlinger, H., Streibel, Th., Suntz, R., Bockhorn, H., 1998. Two-dimensional imaging of soot volume fractions, particle number densities, and particle radii in laminar and turbulent diffusion flames. Proc. Combust. Inst. 27 (1), 1613-1621.

Gerrard, J. H., 1963. An experimental investigation of the initial stages of the dispersion of dust by shock waves. J. Applied Phys. 14 (4), 186.

Gouldin, F. C., 1987. An application of fractals to modeling premixed turbulent flames Combust. Flame 68 (3), 249-266.

Gouldin, F. C., Bray, K. N. C., Chen, J. Y., 1989. Chemical closure model for fractal flamelets Combust. Flame 77 (3-4), 241-259.

Gülder, Ö. L., 1991. Turbulent premixed combustion modelling using fractal geometry Proc. Combust. Inst. 23 (1), 835-842. 
Habib, Z. G., Vervisch, P. 1988. On the refractive index of soot at flame temperature. Combust. Sc. Techol. 59 (4-6), 261-274.

Hailwood, M., Gawlowski, M., Schalau, B., Schönbucher, A., 2009. Conclusions drawn from the buncefield and naples incidents regarding the utilization of consequence models. Chem. Eng. Technol. 32 (2), 207-231.

Hardee, H. C., Lee, D. O., Benedick, W. B. 1978. Thermal hazard from LNG fireballs. Combust. Sc. Techol. 17 (5-6), 189-197.

Holbrow, P., Hawksworth, S. J., Tyldesley, A., 2000. Thermal radiation from vented dust explosions. J. Loss Prevent. Proc. 13 (6), 467-476.

Hottel, H., 1958. Radiant Heat Transmission. McGraw-Hill, Singapore.

Howell, J. R., Siegel, R., Mengüç, M. P., 2011. Thermal Radiation Heat Transfer, 5th ed. Taylor \& Francis/CRC New York.

Jones, W. P., Lindstedt, R. P., 1988. Global reaction schemes for hydrocarbon combustion. Combust. Flame 73 (3), 233-249.

Kerstein, A. R., 1988. Fractal Dimension of Turbulent Premixed Flames. Combust. Sci. Technol. 60 (4-6), 441-445.

Klemens, R., Zydak, P., Kaluzny, M., Litwin, D., Wolanski, P., 2006. Dynamics of dust dispersion from the layer behind the propagating shock wave. J. Loss Prevent. Proc. 19 (2-3), 200-209.

Lee, S. C., Tien, C. L., 1981. Optical constants of soot in hydrocarbon flames. Proc. Combust. Inst. 18 (1), 1159-1166. 
Lefebvre, A. H., 1984. Flame radiation in gas turbine combustion chambers. Int. J. Heat Mass Tran. 27 (9), 1493-1510.

Lindstedt, R. P., Meyer, M. P., 2002. A dimensionally reduced reaction mechanism for methanol oxidation. Proc. Combust. Inst. 29 (1), 1395-1402.

Lindstedt, R. P., Milosavljevic, V. D., Persson, M., 2011. Turbulent burning velocity predictions using transported pdf methods. Proc. Combust. Inst. 33 (1), 1277-1284.

Lu, Shou-Xiang, Guo, Zi-Ru, Li, Yuan-Long, Fan, Wei-Cheng, Zhang, Li, Yang, Li-Zhong, Wang, Qing-An, 2002. Proc. Combust. Inst. 29 (2), 28392846.

Ludwig, C. B., Malkmus, W., Reardon, J. E., Thomson, J. A. L., Goulard, R., 1973. Handbook of infrared radiation from combustion gases. NASASP-3080.

Mandelbrot, B., 1983. The fractal geometry of nature. Freeman and Company, New York, ISBN 0-7167-1186-9

Mason, P. S., Fleischmann, C. M., Rogers, C. B., McKinnon, A. E., Unsworth, K., Spearpoint, M., 2009. Estimating thermal radiation fields from 3d flame reconstruction. Fire Technol. 45 (1), 1-22.

McEnally, C. S., Köylü, Ü. Ö., Pfefferle, L. D., Rosner, D. E., 1997. Soot volume fraction and temperature measurements in laminar nonpremixed flames using thermocouples. Combust. Flame 109 (4) 701-720. 
Mengüç, M. P., Cummings, W. G., Viskanta, R., G., 1986. Radiative transfer in a gas-turbine combustor. J. Propul. Power 2 (3), 241-247.

Moore, S. R., Weinberg, F. J., 1981. High propagation rates of explosions in large volumes of gaseous mixtures. Nature 290 (5801), 39-40.

Moore, S. R., Weinberg, F. J., 1983. A study of the role of radiative ignition in the propagation of large explosions. Proc. R. Soc. Lond. A 385 (1789), $373-387$.

Moore, S. R., Weinberg, F. J., 1987. Further studies of the role of radiative ignition in the propagation of large explosions. Proc. R. Soc. Lond. A 409 (1836), 1-20.

Morley, C., Gaseq, A Chemical Equilibrium Program for Windows (version 0.79); available for download at http://www.arcl02.dsl.pipex.com/gseqmain.htm, accessed in April 2013.

Mudan, K. S., 1987. Geometric view factors for thermal radiation hazard assessment. Fire Safety J. 12 (2) 89-96.

Najjar, Y. S. H., 1 1985. Engineering prediction of soot concentration in the primary zone of the gas turbine combustor. Fuel 64 (1), 93-98.

Nathan, G. J., Kalt, P. A. M., Alwahabi, Z. T., Dally, B. B., Medwell, P. R., Chan, Q. N., 2 2012. Recent advances in the measurement of strongly radiating, turbulent reacting flows. Progr. Energ. Combust. Science 38 (1), 41-61. 
Oran, E. S., Williams, F. A., 2012. The physics, chemistry and dynamics of explosions. Proc. R. Soc. Lond. A 370 (1960), 534-543.

Rew, P. J., Hulbert, W. G., Deaves, D. M., 1997. Modelling of thermal radiation from external hydrocarbon pool fires. Process Saf. Environ 75 (2), 81-89.

Roberts, A. F., 1981. Thermal radiation hazards from releases of LPG from pressurised storage. Fire Safety J. 4 (3), 197-212.

Roberts, T., Gosse, A., Hawksworth, S., 2000. Thermal radiation from fireballs on failure of liquefied petroleum gas storage vessels. Process Saf. Environ. 78 (3), 184-192.

Shaddix, C., Williams, T., 2007. Soot: Giver and taker of light. Am. Sci. $95(3), 232$.

Shirvill, L. C., Roberts, T. A., Royle, M., Willoughby, D. B., Gautier, T., 2012. Safety studies on high-pressure hydrogen vehicle refuelling stations: Releases into a simulated high-pressure dispensingarea. Int. J. Hydrogen Energ. 37 (8), 6949-6964.

Smyth, K. C., Shaddix, C. R., 1996. The elusive history of $\tilde{m}=1.57-0.56 \mathrm{i}$ for the refractive index of soot. Combust. Flame 107 (3), 314-320.

The Steel Construction Institute, 2014. Buncefield Explosion Mechanism Joint Industry Project: Phase II - Dispersion and Explosion Characteristics of Large Vapour Clouds (Volumes 2). (http://www.fabig.com/videopublications/OtherPublications). 
Tien, C. L., Lee, S. C., 1982. Flame radiation. Progr. Energ. Combust. 8 (1), $41-59$.

Van de Hulst, H., 1957. Light Scattering by Small Particles. Wiley, New York.

Viskanta, R., Mengüç, M. P., 1987. Radiation heat transfer in combustion systems. Progr. Energ. Combust. 13 (2), 97-160.

Wal, R. L., Weiland, K. J., 1994. Laser-induced incandescence: Development and characterization towards a measurement of soot-volume fraction. Applied Phys. B 59 (4), 445-452.

Wiedenhoefer, J. F., Reitz, R. D., 2003. A multidimensional radiation model for diesel engine simulation with comparison to experiment. Numer. Heat Tr. A-Appl. 44 (7), 665-682.

Yoshikawa, T., Reitz, R. D., 2009. Effect of radiation on diesel engine combustion and heat transfer. J. Therm. Sci. Tech.-Jpn. 4 (1), 86-97.

Yuen, W. W., Tien, C. L., 1977. A simple calculation scheme for the luminous-flame emissivity. Proc. Combust. Inst. 16 (1), 1481-1487. 